\title{
Efeitos da acumulação de sujeira sobre o desempenho de módulos fotovoltaicos
}

\section{Effects of dust accumulation on the perfomace of photovoltaic modules}

\section{Efectos de la acumulación de suciedad sobre el rendimiento de módulos fotovoltaicos}

\section{Effets de l'accumulation de saleté sur les performances des modules photovoltaïques}

Danielly Norberto Araujo iD danielly.araujo@ee.ufcg.edu.br Departamento de Eng. Elétrica, Universidade Federal do

Ceará - UFC

Paulo Cesar Marques de Carvalho iD carvalho@dee.ufc.br Departamento de Eng. Elétrica, Universidade Federal do

Ceará - UFC

Ivonne Montero Dupont iD ivonne.mdupont@gmail.com Departamento de Eng. Elétrica, Universidade

Federal do

Ceará - UFC

\section{Resumo}

O interesse no uso de energia solar para geração de eletricidade tem conduzido pesquisas sobre os parâmetros que interferem no desempenho de módulos fotovoltaicos (FV). A sujeira é um dos parâmetros que impacta negativamente, pois sua acumulação impede que a irradiação solar incida diretamente na superfície dos módulos. Vários estudos têm sido realizados retratando os impactos da sujeira em diferentes lugares do mundo. Assim, o presente artigo tem como objetivo proporcionar uma visão das experiências brasileiras e internacionais que abordam o tema. Além disso, é apresentado um estudo sobre o impacto da sujidade no desempenho de uma planta FV instalada no campus do Pici da UFC, em Fortaleza, Ceará. Os resultados mostram que, devido à sujidade, a perda máxima de eficiência da planta FV é de $16,52 \%$, enquanto a perda de eletricidade gerada chega a $11,71 \%$ para um período de 17 dias sem chuva. Após uma chuva de $0,6 \mathrm{~mm}$, é registrado um aumento de $9,09 \%$ da eletricidade gerada e de $6,20 \%$ da eficiência da planta.

Palavras-chave: Energia solar. Módulos fotovoltaicos. Sujeira.

\section{Abstract}

The interest in solar energy for electricity generation has led studies on parameters that interfere in the photovoltaic (PV) modules' performance. The dust is one of those parameters that impact negatively since its accumulation blocks the direct solar irradiation on the modules' surface. Several studies have already been carried out to describe the impacts of dust in different sites around the world. Thus, the present paper aims to provide a view of Brazilian and international experiments in this area. Furthermore, it is presented a study on the soiling impact on a PV plant performance located at Pici Campus of the UFC in Fortaleza, Ceará. The results show that due to soiling, the maximum $P V$ plant efficiency loss is $16.52 \%$ while the generated electricity loss reaches $11.71 \%$ for 17 days of dry weather. After a $0.6 \mathrm{~mm}$ rain, there is an increase of $9.09 \%$ on the generated electricity and $6.20 \%$ on the PV plant efficiency.

Keywords: Solar energy. Photovoltaic Modules. Dust.

\section{Resumen}

El interés en el uso de energía solar para generar electricidad viene conduciendo investigaciones sobre los parámetros que influyen en el rendimiento de módulos fotovoltaicos (FV). La suciedad es uno de los parámetros que impacta de forma negativa, porque su acumulación impide que la irradiación solar incida directamente en la superficie de los módulos. Varios estudios retratan los impactos de la suciedad en diferentes lugares del mundo. Así que, el presente trabajo tiene el objetivo de proporcionar una mirada de las experiencias brasileñas 
e internacionales que tratan del tema. Además de eso, se presenta un estudio sobre el impacto de la suciedad en el rendimiento de una planta FV instalada en el campus del Pici de la UFC, en Fortaleza, Ceará. Los resultados muestran que, debido a la suciedad, la perdida máxima de eficiencia de la planta FV es de $16,52 \%$, mientras que la pérdida de electricidad generada llega a $11,71 \%$ para un período de 17 días sin lluvia. Después de una lluvia 0,6mm, es registrado un aumento de $0,09 \%$ de la electricidad generada y de $6,20 \%$ de la eficiencia de la planta.

Palabras-clave: Energía solar. Módulos fotovoltaicos. Suciedad.

\section{Résumé}

L'intérêt à l'utilisation de l'énergie solaire pour produire d'électricité mène souvent des recherches sur les paramètres qui interfèrent avec les performances des modules photovoltaïques. La saleté est l'un des paramètres qui ont un impact négatif, car son accumulation empêche le rayonnement solaire d'émettre l'énergie directement dans la surface des modules. Plusieurs études ont été réalisées en décrivant les impacts de la saleté dans différentes parties du monde. Ainsi, cet article vise à fournir un regard des expériences brésiliennes et internationales qui traitent de la question. En plus, une étude est présentée sur l'impact de la saleté sur la performance d'une installation photovoltaïque installée sur le campus Pici de l'UFC à Fortaleza, à l'état du Ceará, au Brésil. Les résultats montrent que, à cause de la saleté, la perte d'efficacité maximale de l'installation photovoltaïque est de $16,52 \%$, tandis que la perte d'électricité générée atteint $11,71 \%$ pour une période de 17 jours sans pluie. Après une précipitation de $0,6 \mathrm{~mm}$, est enregistrée une augmentation de $9,09 \%$ de l'électricité produite, ainsi que $6,20 \%$ de l'efficacité des centrales.

Mots-clés: L'énergie solaire. Modules photovoltaïques. Saleté

\section{Introdução}

O interesse e o uso da energia solar para produção de eletricidade estão cada vez mais crescentes. Essa tendência tem sido impulsionada pela importância da sustentabilidade (SAID et al., 2018), redução dos custos dos sistemas FV e políticas específicas para seu uso. Devido ao aumento do interesse nos mercados globais de energia sustentável, a energia solar está atraindo grande atenção de pesquisadores, o que tem acarretado no desenvolvimento de novas e sofisticadas tecnologias de células e módulos FV (JHA; TRIPATHY, 2019). Apesar do desenvolvimento de materiais de alto desempenho, a maior desvantagem dos sistemas FV continua sendo sua eficiência limitada na conversão de energia solar (RAZYKOV et al., 2011). Atualmente, a maioria dos módulos FV disponíveis no mercado é composta por células FV com eficiência de conversão de cerca de $14 \%$ a $25 \%$ (KALDELLIS; KAPSALI; KAVADIAS, 2014).

A eficiência das células é classificada sob condições de teste padrão (STC - Standard Test Conditions): irradiância de $1000 \mathrm{~W} / \mathrm{m}^{2}$, massa de ar (AM - air mass) 1,5 e temperatura do módulo a $25^{\circ} \mathrm{C}$, mas essas condições raramente são encontradas sob condições operacionais reais. Assim, as principais condições climáticas que afetam o desempenho dos módulos FV incluem: irradiação solar; temperatura; velocidade e direção do vento; umidade relativa e poeira (JAMIL et al., 2017). Segundo Kumar, Sinha e Pandey (2017), os fatores que mais afetam a potência de saída dos módulos são a irradiação solar e a temperatura ambiente. Outro fator que também afeta é o acúmulo de sujidade na superfície do módulo, que evita que a irradiação solar incida diretamente sobre sua superfície (JAMIL et al., 2017).

A sujidade ou sujeira pode ser composta por uma infinidade de substâncias, sendo a mais comum delas a poeira (GHAZI; SAYIGH; IP, 2014). Poeira é definida como qualquer material particulado, com menos de $500 \mu \mathrm{m}$ de diâmetro, que entra na atmosfera por diferentes fontes: levantada pelo vento, escapamento de 
veículos, erupções vulcânicas e poluição do ar. Além disso, também pode conter pequenas quantidades de pólen, fungos, bactérias, vegetação, microfibras e, mais comumente, minerais orgânicos, como areia, argila e calcário erodido (DARWISH et al., 2015).

A avaliação detalhada dos efeitos da sujeira é um problema verdadeiramente complexo devido aos muitos fatores influenciadores, como parâmetros ambientais (concentração de poeira no ar, umidade relativa, temperatura ambiente, velocidade e direção do vento), propriedades do módulo FV (propriedades do vidro), características do local e da instalação (ângulo de inclinação e orientação) e outros (ILSE et al., 2018). Na Figura 1 são apresentados os fatores influenciadores para acúmulo de sujeira.

Figura 1 - Fatores influenciadores para acúmulo de sujeira na superfície de módulos FV.

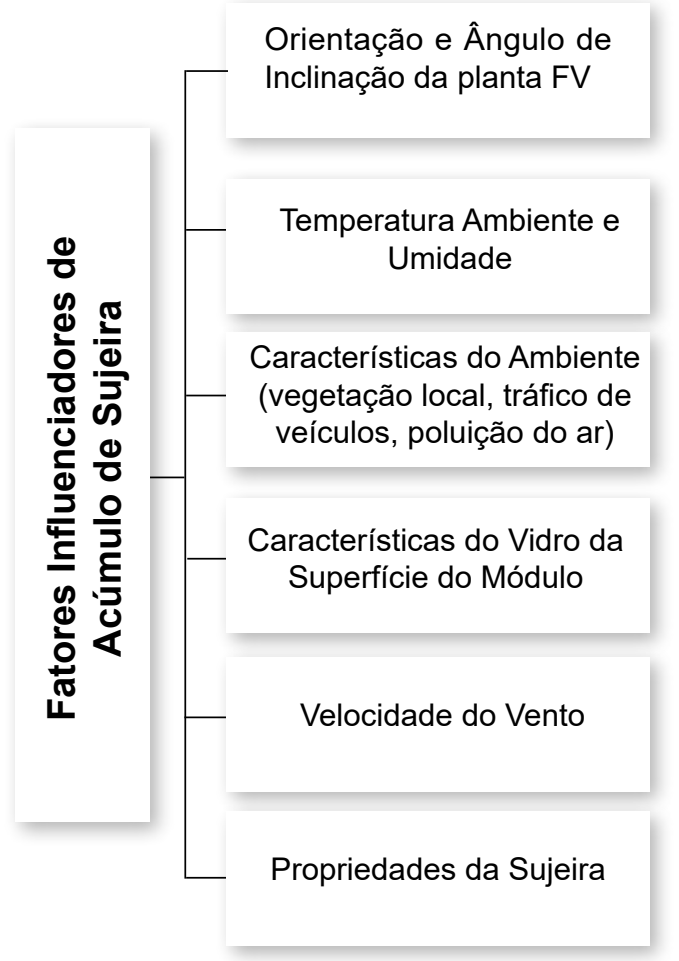

Fonte: Adaptado de Jamil et al., 2017.

O efeito do acúmulo de sujeira é minimizado pela limpeza manual periódica, ou pela incidência de chuvas, e pelo vento, sendo observado que chuvas frequentes podem tornar a quantidade de sujeira acumulada pouco impactante, se não desprezível. Para que isso ocorra, um ângulo de inclinação de pelo menos $10^{\circ}$ normalmente é suficiente (ARAÚJO, 2016). Vários estudos já foram realizados retratando os impactos da sujeira no desempenho de plantas FV em diferentes lugares do mundo. Alguns trabalhos, por exemplo, são de revisão bibliográfica, cujo objetivo é exemplificar e descrever outros trabalhos. Mussard e Amara (2018) apresentam resultados experimentais de plantas FV sob condições de sujeira e clima árido. Costa; Diniz e Kazmerski (2016, 2018), Jamil et al. (2017), e Said et al. (2018) realizam uma revisão de artigos sobre os fatores que influenciam o desempenho do módulo FV e os diferentes métodos de mitigação.

Segundo Jaszczur (2018), devido ao número de parâmetros que influenciam a sujeira, grande parte das informações disponíveis na literatura se aplicam apenas ao local específico em que o trabalho experimental foi realizado. Nesse contexto, o presente trabalho tem como objetivo realizar uma revisão bibliográfica de artigos publicados em periódicos e congressos sobre o impacto da sujidade em plantas FV; adicionalmente, é analisado o impacto da sujidade da planta FV instalada no Laboratório de Energias Alternativas da Universidade 
Federal do Ceará (LEA-UFC), em Fortaleza, Ceará. O artigo está organizado da seguinte forma: a metodologia é apresenta na Seção 2. As condições que afetam o desempenho FV são apresentadas na Seção 3. Na Seção 4 é apresentado o estado da arte dos estudos sobre os impactos da sujeira na geração FV, dividido em experimentos brasileiros e internacionais. Na seção 5 é avaliado o impacto da sujidade em módulos FV instalados em Fortaleza - Ceará e, na seção 6, as considerações finais são feitas.

\section{Metodologia}

Sujidade é um parâmetro ambiental que afeta o desempenho de módulos FV e possui diversos fatores influenciadores, sendo assim sua avaliação detalhada complexa e específica do local do estudo. Uma das maneiras de avaliar o comportamento do módulo FV é a partir da sua curva I-5, que possibilita detectar anomalias em seu desempenho. Outra maneira de avaliação é a partir das métricas, sendo as mais utilizadas para análise da sujeira no desempenho das plantas FV as seguintes (TONOLO; MARIANO, 2018; PAUDYAL; SHAKYA, 2016; JASZCZUR et al., 2018):

- Eficiência (E): capacidade do módulo de converter energia solar em energia elétrica.

$$
E=\frac{P \max }{G A}
$$

- é a potência máxima diária, G a irradiação solar e "A" a área do módulo FV.

- Redução da eficiência: comparação da eficiência entre o módulo sujo e o limpo.

$$
\% \text { redução }=\frac{E_{\text {limpo }}-E_{\text {sujo }}}{E_{\text {limpo }}} \times 100
$$

- Relação de sujidade: relação entre a potência máxima diária do módulo sujo e a potência máxima diária do módulo limpo.

$$
S R=\frac{\text { Pmax }_{\text {sujo }}}{\text { Pmax }_{\text {limpo }}}
$$

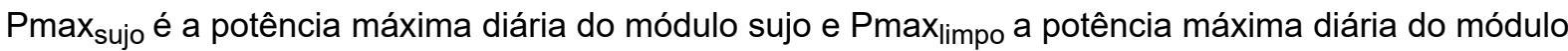
limpo. Quando SR = 1, o módulo está limpo.

- YIELD (Produtividade): relação entre a energia elétrica (kWh) entregue e a potência instalada (kWp) da planta FV.

$$
\text { YIELD }=\frac{\text { Energiaentregue }}{\text { Potênciainstalada }}
$$

- Relação de desempenho (PR - performance ratio): comparação da produção real da planta FV em relação à eletricidade que a planta poderia ter gerado se não houvessem perdas (Irradiância,referência $=1000 \mathrm{~W} / \mathrm{m}^{2}$ ).

$$
P R=\frac{Y I E L D}{\frac{\text { Irradiação }}{\text { Irradiância,referência }}}
$$

No presente artigo, a fim de analisar os principais resultados de pesquisas desenvolvidas em diferentes lugares do mundo, uma revisão de artigos publicados em congressos e periódicos, entre 2016 e 2019, é realizada. A revisão é dividida em três partes: estudos nacionais, estudos internacionais e análise geral dos artigos. A última parte tem como objetivo expor dados, como porcentagem dos artigos que analisam a composição química e o tamanho das partículas, por exemplo.

Além disso, um estudo para avaliar o impacto da sujidade em uma planta FV conectada à rede elétrica é apresentado. A planta FV está instalada no Laboratório de Energias Alternativas da Universidade Federal 
do Ceará (LEA-UFC), campus do Pici, com coordenadas UTM (Universal Transversa de Mercator): latitude $3^{\circ}$ 44' $15^{\prime \prime}$ S e longitude 38 34' 22" W. Na Figura 2 é mostrada a localização do LEA-UFC, evidenciando que o laboratório está localizado em um ambiente urbano, próximo a uma avenida de grande movimentação e com vegetação nos arredores.

Figura 2 - Localização do LEA-UFC.

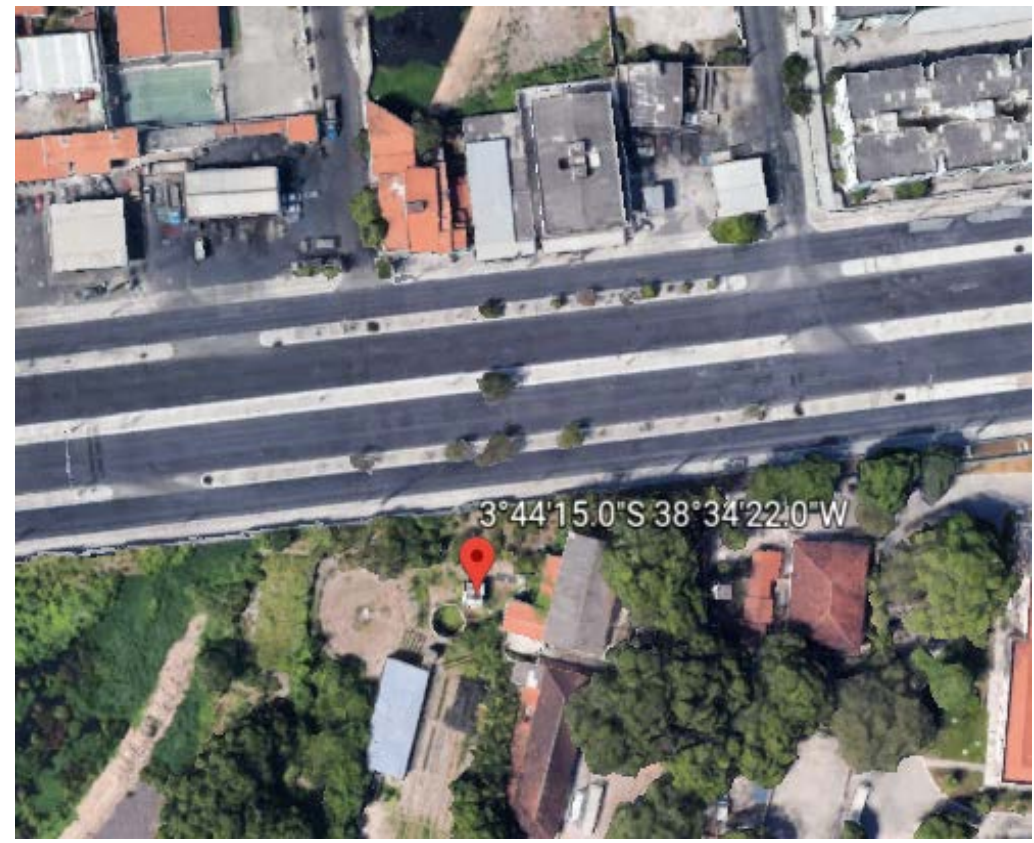

Fonte: Google earth, 2019.

A planta FV do LEA-UFC possui potência instalada de $3,9 \mathrm{kWp}$, subdividida em 2 strings de 6 módulos FV cada, conforme Figura 3. Na Tabela (1) são mostradas as especificações do módulo utilizado.

Figura 3 - Planta FV do LEA-UFC.

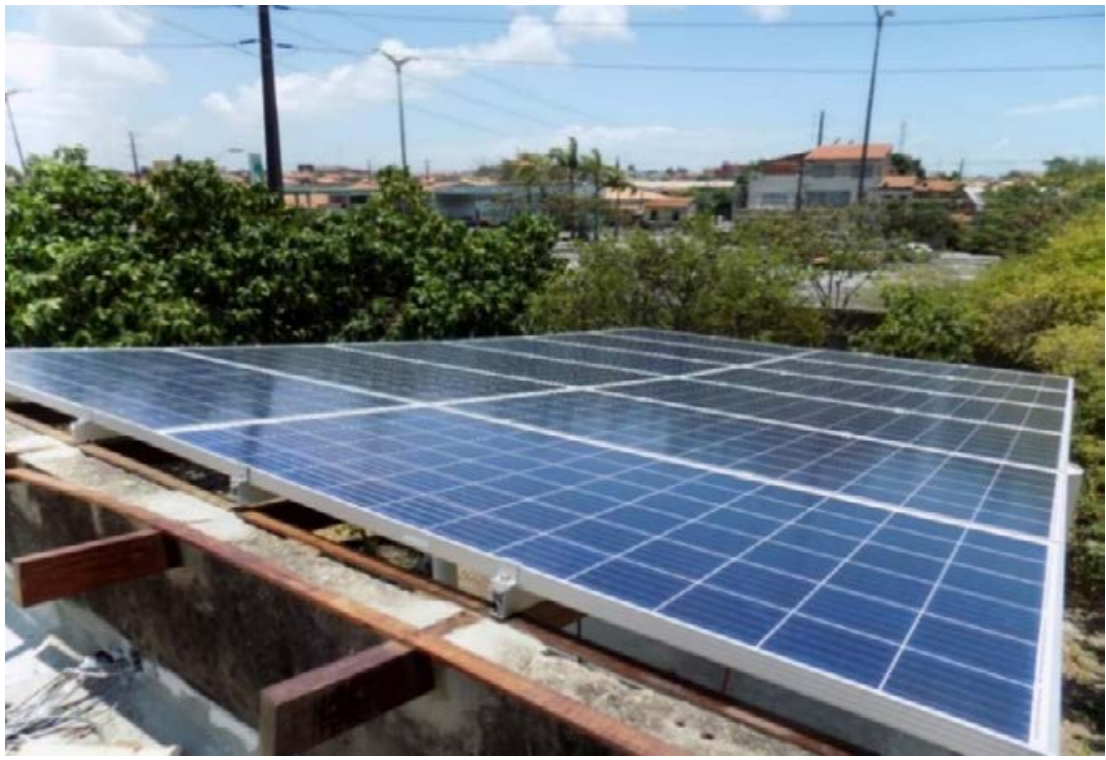

Fonte: Autoria própria, 2019. 
Tabela 1: Especificações técnicas do módulo JKM330PP.

\begin{tabular}{l|c}
\hline Potência no mpp (Pmpp) & $330 \mathrm{Wp}$ \\
\hline Tensão no mpp (Vmpp) & $37,8 \mathrm{~V}$ \\
\hline Corrente no mpp (Impp) & $8,74 \mathrm{~A}$ \\
\hline Tensão de circuito aberto (Voc) & $46,9 \mathrm{~V}$ \\
\hline Corrente de curto circuito (Isc) & $9,14 \mathrm{~A}$ \\
\hline Eficiência do módulo (\%) & $17,01 \%$ \\
\hline Dimensões do módulo & $1956 \times 992 \times 40 \mathrm{~mm}$ \\
\hline Número de células & 72 \\
\hline
\end{tabular}

Fonte: Jinko Solar, 2019.

No presente estudo, dados de potência máxima atingida pelos módulos FV, de eletricidade gerada e irradiação, de dias de céu claro selecionados antes e depois de um período com chuva, são utilizados para o cálculo da eficiência dos módulos e dos parâmetros YIELD, PR e SR. Uma comparação desses parâmetros antes e depois da ocorrência de uma chuva é realizada.

Para aquisição de dados, dois sistemas independentes são utilizados. Para coleta dos dados de geração de eletricidade utiliza-se um datalogger com conexão com o inversor feita por comunicação via RS485. Os dados coletados são armazenados a cada 10 minutos no servidor web e podem ser exportados no formato xls. Utilizando um sistema SCADA com um controlador lógico programável (CLP), modelo Twido TWDLCE40DRF, e um piranômetro, a aquisição de dados de irradiância é realizada. O piranômetro usado é do modelo LP02, com uma sensibilidade de $18,56^{*} 10^{-6} \mathrm{~V} /\left(\mathrm{W} / \mathrm{m}^{2}\right)$. Na Figura 4 é apresentado o inversor (a), o CLP (b) e o piranômetro (c) utilizados.

Figura 4 - Inversor (a), CLP (b) e piranômetro (c) utilizados no experimento.

(a)

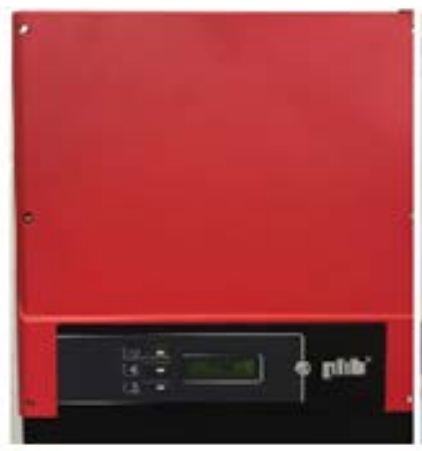

Fonte: Autoria própria, 2019. (b)

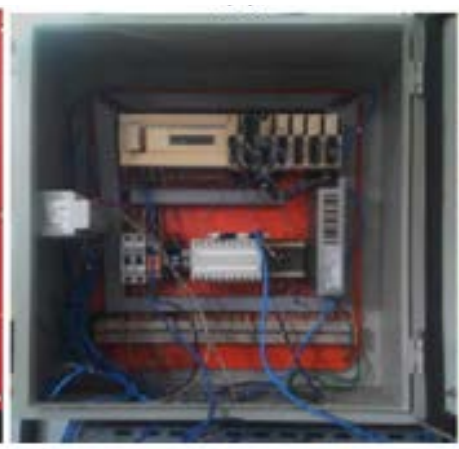

(c)

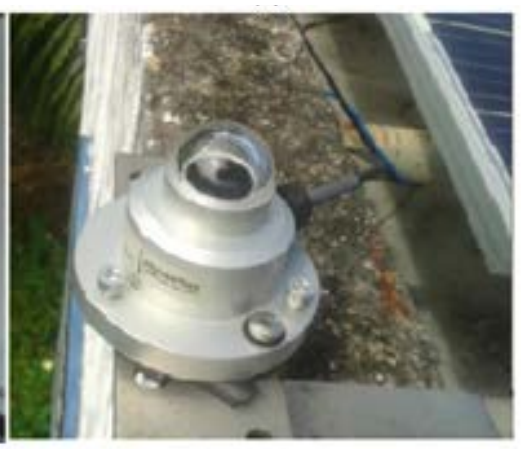

Os dados de chuva são fornecidos pela Estação Agroclimatológica de Fortaleza, localizada no Centro de Ciências Agrárias da UFC, campus do Pici, cujas coordenadas UTM são: latitude de $3^{\circ} 44^{\prime} 15^{\prime \prime}$ e e longitude de $38^{\circ} 34^{\prime} 18^{\prime \prime}$ W. Esses dados são validados com os dados de chuva em Fortaleza fornecidos pela Fundação Cearense de Meteorologia e Recursos Hídricos (Funceme).

\section{Condições que afetam o desempenho dos módulos FV}

Uma das formas de observar e avaliar o funcionamento de um módulo FV é a partir da curva I-V, que relaciona a corrente e a tensão. Através dessa curva é possível extrair os principais parâmetros elétricos do módulo: tensão de circuito aberto $\left(\mathrm{V}_{\mathrm{OC}}\right)$, corrente de curto-circuito $\left(\mathrm{I}_{\mathrm{SC}}\right)$, ponto de máxima potência $\left(\mathrm{P}_{\mathrm{MPP}}\right)$, tensão 
de máxima potência $\left(\mathrm{V}_{\mathrm{MPP}}\right)$ e corrente de máxima potência $\left(\mathrm{I}_{\mathrm{MPP}}\right)$. A curva I-V é traçada através de testes sob condições padronizadas; sob condições diferentes, a curva é diferente daquela fornecida pelo fabricante. A partir da curva é possível detectar anomalias no desempenho do módulo FV. Na Figura 5 são mostradas diferentes curvas I-V para diferentes valores de irradiância e temperatura ambiente.

Figura 5 - Curvas I-V para distintos valores de irradiância solar e temperatura $=25^{\circ} \mathrm{C}$ e para distintos valores de temperatura e irradiância $=1000 \mathrm{~W} / \mathrm{m}^{2}$, respectivamente.
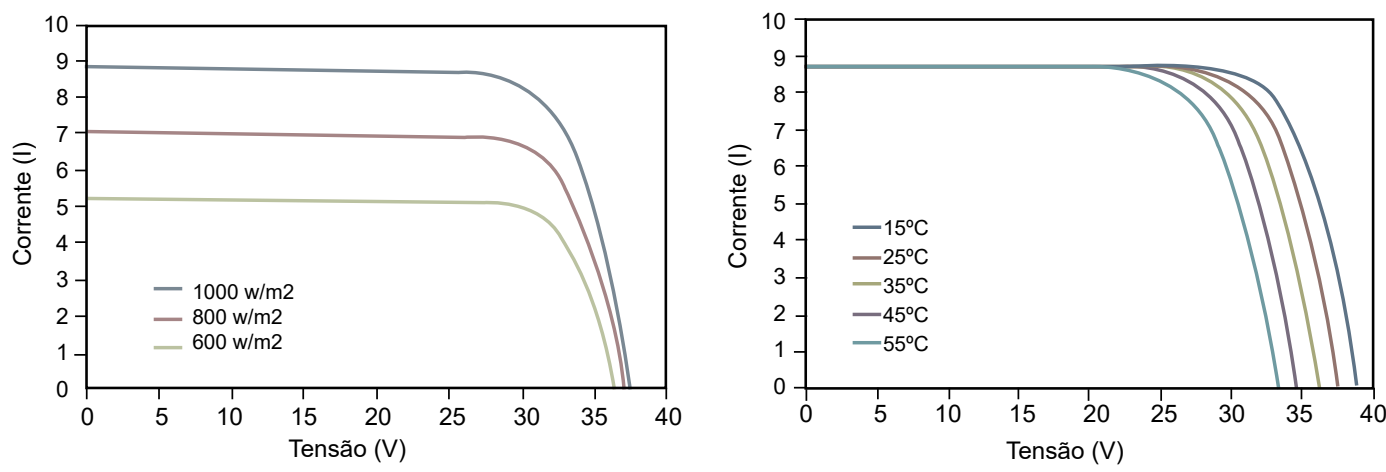

Fonte: Solar Brasil, 2019.

A relação da irradiância com a corrente gerada pelo módulo FV é diretamente proporcional e quase não afeta sua tensão. Já a temperatura tem efeito negativo no desempenho do módulo $\mathrm{FV}$, afetando sua tensão gerada, em que quanto maior a temperatura do módulo FV, menor a tensão gerada. A temperatura tem efeito desprezível na corrente. Os diferentes modos de funcionamento afetam as características I-V do módulo FV de maneiras diferentes, deixando assinaturas distintas durante a sua operação. A Figura 6 indica como os diferentes desvios na curva podem ser lidos (SARIKH et al., 2018).

Figura 6 - Curvas I-5 para diferentes condições de funcionamento do módulo FV.

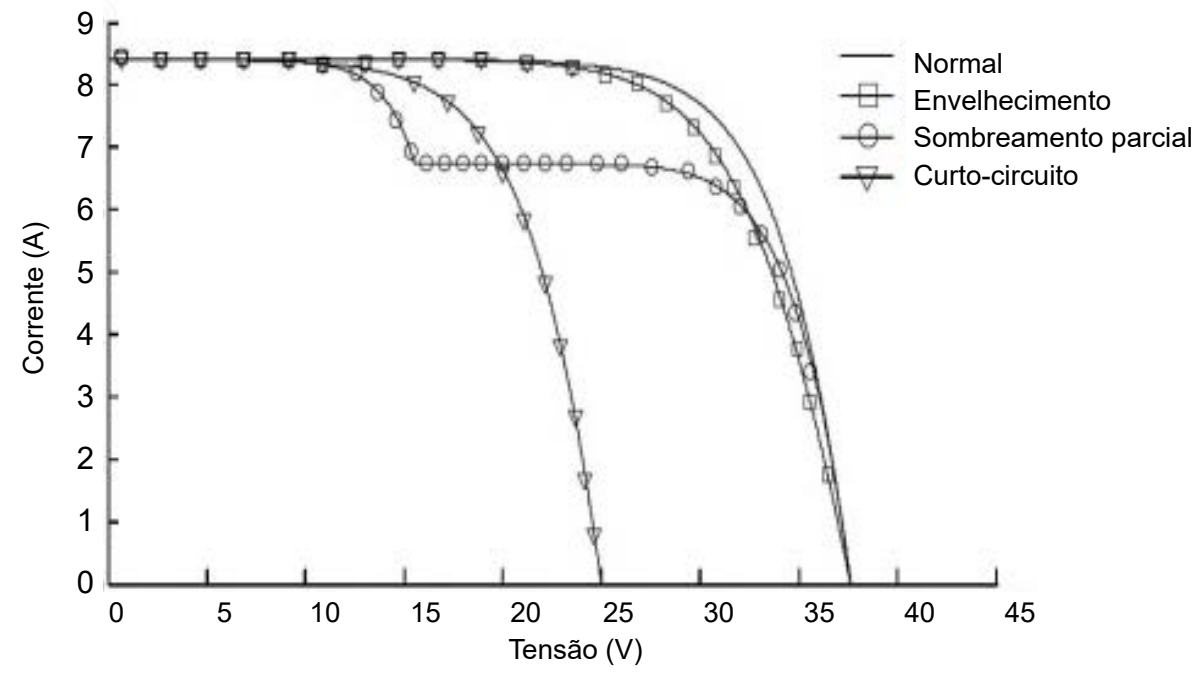

Fonte: Adaptado de Sarikh et al., 2018.

A degradação, definida pela deterioração gradual das características de um componente ou de um sistema (LANNOY; PROCACCIA, 2005), também é um modo de funcionamento que pode afetar a produção de eletricidade. De acordo com Munoz et al. (2011), os principais tipos de degradação que podem ocorrer em um módulo são: descoloração, delaminação, quebras e rachaduras, pontos quentes e bolhas. 
A sujeira, condição não ideal objeto do presente estudo, reduz a irradiação solar efetiva devido à absorção, dispersão e reflexão por contaminantes presentes na superfície do módulo FV (SINHA et al., 2014). Na curva I-V, o parâmetro mais afetado é a corrente do módulo $F V$, já que a sujeira não permite que a irradiação incida sobre a superfície do módulo, sendo proporcional à corrente gerada. A Figura 7 apresenta o efeito do acúmulo de sujeira na superfície de módulos FV no Egito.

Figura 7 - Acúmulo de sujeira em módulos FV instalados no Egito.

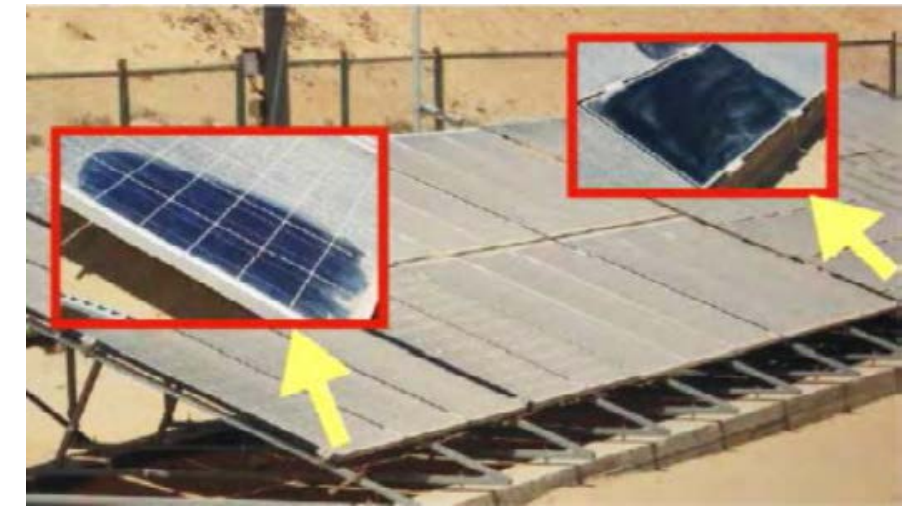

Fonte: Ghazi; Sayigh e Ip, 2014.

Segundo John (2015), o processo de sujeira envolve as seguintes etapas:

- Transporte de sujeira: depende, principalmente, da velocidade do vento e do tamanho das partículas de sujeira.

- Adesão inicial: depende das propriedades da partícula de superfície e poeira, de sua composição química, do grau de suavidade ou rugosidade, das propriedades elétricas (condutividade e carga), da orientação, das propriedades ópticas, da dureza/maciez, temperatura, dmovimento mecânico e de seu micro ou nano características.

- Mudanças nos mecanismos de adesão inicial: tendem a mudar com o tempo devido à influência do meio ambiente.

- Alterações na superfície: os mecanismos de adesão podem alterar a superfície por meio de intemperismo ou levando a mais acumulação.

- Métodos restaurativos: chuva e limpeza manual com água.

\section{Estado da arte dos estudos sobre os impactos da sujeira na geração FV}

\section{Estudos brasileiros}

Hickel et al. (2016) retratam a influência do acúmulo de sujeira nas seguintes tecnologias de módulos FV: monocristalina (m-Si), polocristalina ( $p-S i)$, silício amorfo (a-Si), microcristalino ( $\mu c-S i)$, e disseleneto de cobre, índio e gálio (CIGS). Os módulos fazem parte de cinco sub-plantas de potência de $2 \mathrm{kWp}$ cada, instaladas no interior da Bahia, em Brotas de Macaúbas (Fig. 8). Na análise são comparadas a potência de saída e a PR dos módulos, antes e depois da limpeza. Em relação à potência, os resultados mostram que, dentre os módulos de silício cristalino, o de $\mathrm{p}$-Si tem perdas 2,5 vezes maiores que o de $\mathrm{m}$-Si, e dentre os módulos de filmes finos, o de maior e menor perdas é o de a-Si e o de CIGS, respectivamente. Comparando a PR, o módulo que tem o maior desempenho é o de p-Si, na tecnologia de silício cristalino, e os de $\mu c-S i$ e a-Si, na tecnologia de filmes finos. 


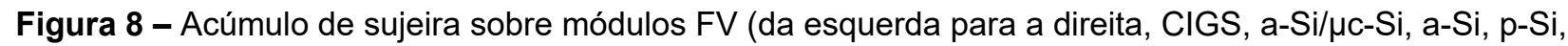
$\mathrm{m}-\mathrm{Si})$.

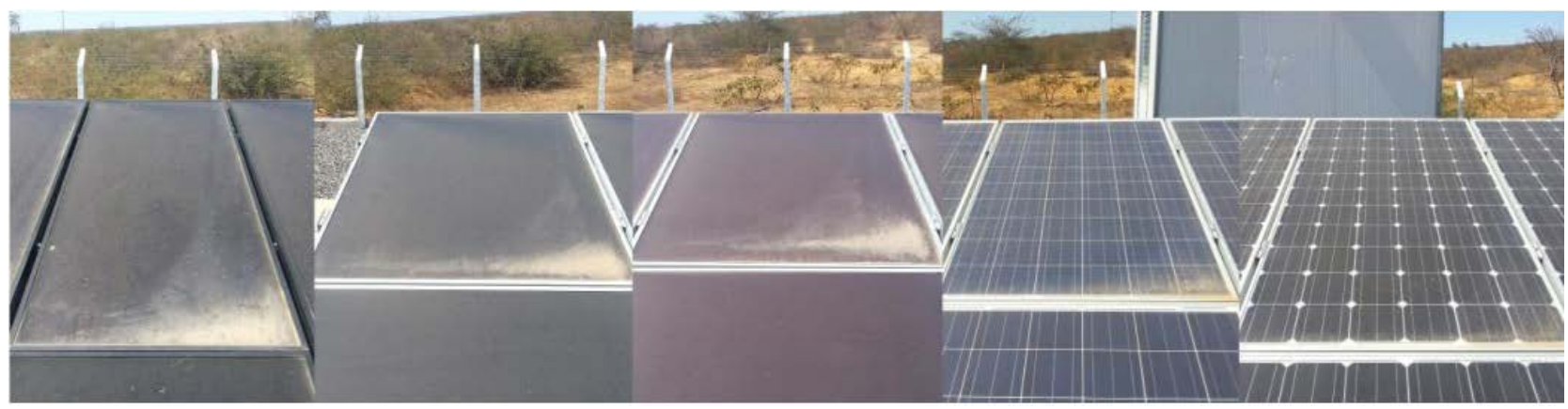

Fonte: Hickel et al., 2016.

Barbosa, Faria e Gontijo (2018), mostram as diferenças entre a produção de eletricidade em módulos FV limpos e sujos conectados à rede elétrica do Centro Universitário de Patos de Minas (UNIPAM), em Patos de Minas, Minas Gerais. A planta FV é composta por 240 módulos p-Si, divididos em três fileiras de 80 módulos, com uma potência total instalada de $12 \mathrm{kWp}$. No experimento, a fileira 3 foi limpa regularmente a cada 7 dias, e as fileiras 1 e 2 foram mantidas sujas. No mês anterior à limpeza, a geração total da planta foi de 1.639,22 kWh, sendo 548,14 kWh no inversor 1, 546,66 kWh no inversor 2 e 547,42 kWh no inversor 3 , ou seja, praticamente se obteve a mesma geração nas três fileiras. No mês em que houve a limpeza dos módulos na fileira 3, a geração total foi de $1.834,62 \mathrm{kWh}$, sendo, 594,8 kWh no inversor 1, 592,13 kWh no inversor 2 e 647,69 kWh no inversor 3. Assim, comparando a geração, a fileira 3 teve um aumento de 10,26\% na produção de eletricidade depois da limpeza dos módulos.

Braga et al. (2018) avaliam os efeitos da sujidade nas grandezas da curva I-V de módulos de diferentes tecnologias: m-Si com potência de $265 \mathrm{Wp}$, e telureto de cádmio (CdTe) com potência de $110 \mathrm{Wp}$. A pesquisa é realizada pelo Grupo de Estudos em Energia da Pontifícia Universidade Católica (PUC) de Minas, Belo Horizonte, Minas Gerais. Para cada padrão diferente de sujidade, a fim de quantificar as perdas de geração de eletricidade, as curvas I-V dos módulos são avaliadas. É concluído que os parâmetros elétricos do módulo de silício cristalino são mais sensíveis ao acúmulo de sujidade se comparados ao módulo de telureto de cádmio. Além disso, apesar da perda de geração, a tecnologia de telureto de cádmio é menos sensível ao aumento de temperatura decorrido do sombreamento gerado pela deposição não uniforme da sujidade.

Costa et al. (2018) quantificam e avaliam as perdas por sujidade em módulos de CdTe e p-Si instalados na PUC Minas, Belo Horizonte, Minas Gerais. São utilizados 2 módulos idênticos de CdTe de 110 Wp, 1 módulo de $\mathrm{p}$-Si de $25 \mathrm{Wp}$ e uma célula de referência de $0,0584 \mathrm{Wp}$. Um dos módulos de telureto de cádmio e a célula de referência são limpos diariamente, enquanto os outros dois são expostos às sujidades. A avaliação é feita pela taxa de sujidade, e durante o período seco e chuvoso. Assim, a taxa de sujidade decresceu ao longo do período seco, atingindo valores em torno de 0,86 para o módulo de p-Si e 0,75 para o de CdTe, aumentando para 1 após precipitações. Comparando os resultados, é observado que a perda por sujidade durante o período seco é maior para a tecnologia CdTe, que pode ser explicado pela diferença de largura da banda das duas tecnologias. A Figura 9 apresenta a estação de sujidade do módulo de CdTe antes e após o período chuvoso, mostrando um acúmulo significativo de contaminantes. 
Figura 9 - Estação de sujidade para a tecnologia de CdTe durante o período seco e após uma precipitação maior que $20 \mathrm{~mm}$, respectivamente.
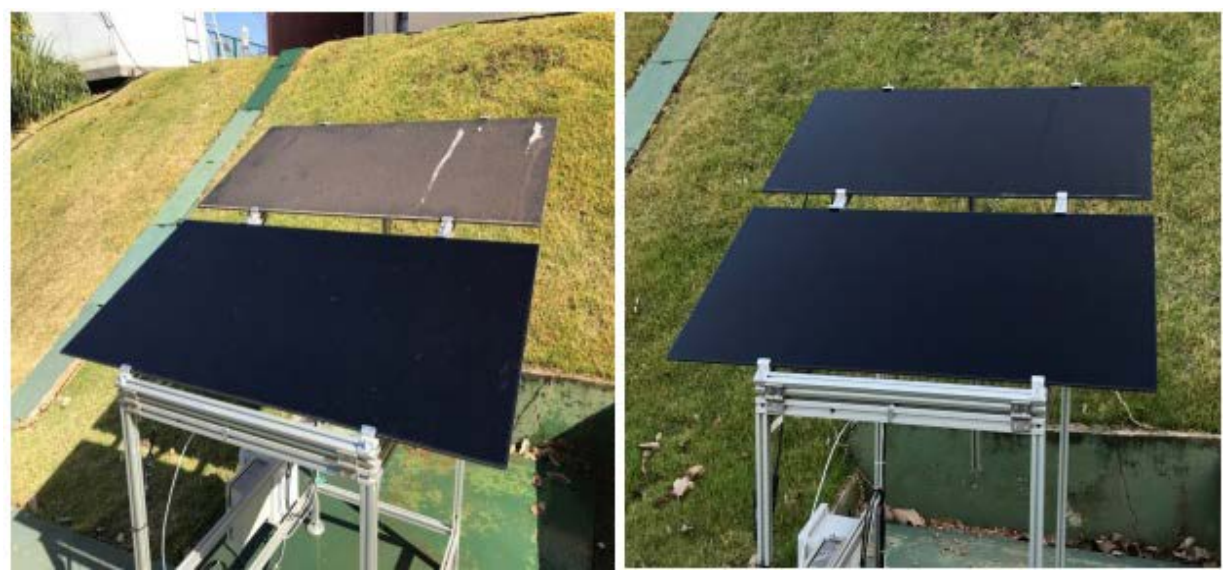

Fonte: Costa et al., 2018.

Soares Júnior, Cruz e Amaral (2018) apresentam um estudo realizado nos módulos da planta FV na Universidade Federal de Montes Claros, Montes Claros, Minas Gerais. A planta é composta por 3 arrays, com 84 módulos FV do tipo p-Si e possui uma potência instalada de 12,6 kWp. A avaliação do impacto da sujidade nos módulos FV é feita a partir da comparação da geração de eletricidade de dois dos arrays, em que um array serve como referência, estando sujo durante todo o experimento, e no segundo array os módulos são limpos com diferentes intervalos de tempo. Com a metodologia utilizada, os autores concluem que não há necessidade de realização de limpeza em um intervalo inferior a 15 dias e que o acúmulo de sujeira, entre 18/09/2017 e 30/09/2017, acarretou uma perda de geração média de 20\%.

Fraga et al. (2018) avaliam o impacto da sujidade na planta FV instalada no estádio de futebol Governador Magalhães Pinto, em Belo Horizonte, Minas Gerais. A planta é composta por 5910 módulos FV m-Si, totalizando uma potência instalada de 1,42 MWp. Os módulos são divididos em 88 setores, dos quais 42 setores têm 75 módulos e os outros 46 têm 60 . Cada setor é dividido em três conjuntos: A, B e C. No estudo, foram escolhidos dois conjuntos, $A$ e $B$, em regiões opostas no estádio e dois setores desses conjuntos foram limpos manualmente a cada cinco dias para servirem como módulos de referência. Uma chuva ocorreu no $23^{\circ}$ dia, de $7 \mathrm{~mm}$, e alguns módulos foram limpos manualmente no $30^{\circ}$ dia. Os grupos A e B foram analisados separadamente $\mathrm{e}$ foi visto que a sujidade reduziu a potência de pico em, aproximadamente, 13,7\% no período seco e $6,5 \%$ no período após a chuva, e também reduziu a produção diária de eletricidade em, aproximadamente, 16,5\% no período seco e $8 \%$ no período após uma chuva. A distribuição do tamanho de partícula dos grupos $A$ e $B$ foi de 35,3 e $28,7 \mu \mathrm{m}$.

Romanholo et al. (2018) analisam as características físico-químicas da sujidade depositada sobre os módulos de uma planta FV na Universidade Federal de Goiás, Goiânia, Goiás. A planta contém 145 módulos do tipo p-Si e possui uma potência instalada de $34 \mathrm{kWp}$. A sujeira dos módulos foi coletada via raspagem com bastonetes de algodão. Foram coletadas 5 amostras de diferentes módulos e a sujidade encontrada apresentou componentes e tamanhos diferentes em cada dessas amostras. Na amostra 1, há alta concentração de silício, alumínio, magnésio. Nas amostras 2 e 3 há alta concentração de carbono e cálcio. Amostra 4 apresenta óxido de enxofre e a 5, carbono, oxigênio, cálcio e nitrogênio. Em relação ao tamanho das partículas, as amostras 1 e 4 apresentam sujidade aglomerada, o que dificultou a estimativa do tamanho, já as amostras 2 e 3 possuem partículas menores do que $10 \mu \mathrm{m}$, e a amostra 5 possui partículas bem menores, na ordem de $100 \mu \mathrm{m}$.

Tonolo e Mariano (2018) estudam os impactos da sujidade em duas plantas FV conectadas à rede elétrica da Universidade Tecnológica Federal do Paraná, Curitiba, Paraná. A primeira planta é na sede centro da Universidade, no prédio do Escritório Verde (EV), composta por 10 módulos p-Si e potência de 2,1 kWp. 
Já a segunda está na sede Neoville, região afastada do centro da cidade, e é composta por 34 módulos p-Si e potência de 10,2 kWp. Foram selecionados cinco dias diferentes, com característica de céu limpo, para análise da irradiação, eletricidade gerada, YIELD e PR. Esses parâmetros foram utilizados para comparar o desempenho da planta com a pré-limpeza e a pós-limpeza. Assim, mesmo a irradiação sendo maior no dia antes da limpeza, o módulo, depois de limpo, gera mais eletricidade do que quando está sujo, além dos parâmetros YIELD e PR terem melhor desempenho. Na Tabela (2) é mostrado um resumo dos parâmetros analisados. As setas, $\uparrow \downarrow$ significam se o parâmetro aumentou ou diminuiu, respectivamente, de um dia para outro.

Tabela 2: Resumo das comparações entre os dias e os parâmetros analisados.

\begin{tabular}{l|l|l|l|l|l|l}
\hline \multirow{2}{*}{ Dias Selecionados } & \multicolumn{2}{|l|}{ Irradiação } & \multicolumn{3}{l}{ Eletricidade Gerada } & \multicolumn{2}{l}{ YIELD } \\
\cline { 2 - 7 } & EV & Neoville & EV & Neoville & EV & Neoville \\
\hline $17 / 06 / 17-13 / 07 / 17$ & $\downarrow 3,07 \%$ & $\downarrow 4,23 \%$ & $\uparrow 6,27 \%$ & $\uparrow 0,81 \%$ & $\uparrow 6,04 \%$ & $\uparrow 0,83 \%$ \\
\hline $13 / 07 / 17-21 / 09 / 2017$ & $\uparrow 36,98 \%$ & $\uparrow 28,60 \%$ & $\uparrow 27,40 \%$ & $\uparrow 16,87 \%$ & $\uparrow 27,47 \%$ & $\uparrow 17,01 \%$ \\
\hline $21 / 09 / 2017-04 / 10 / 2017$ & $\uparrow 7,25 \%$ & $\uparrow 2,97 \%$ & $\uparrow 19,33 \%$ & $\uparrow 12,03 \%$ & $\uparrow 19,41 \%$ & $\uparrow 11,91 \%$ \\
\hline $04 / 10 / 2017-28 / 10 / 2017$ & $\uparrow 3,28 \%$ & - & $\uparrow 3,56 \%$ & - & $\uparrow 3,41 \%$ & - \\
\hline
\end{tabular}

Fonte: Adaptado de Tonolo, Mariano, 2018.

Silva et al. (2019) apresentam aplicações de técnicas de avaliação de sujeira, temperatura e das principais formas de degradação em módulos FV. A planta FV analisada é dividida em 3 arrays, possui uma potência instalada de 10,16 kWp é composta por 48 módulos de 5 modelos diferentes e está instalada na Universidade Federal de Uberlândia (UFU), Uberlândia, Minas Gerais. Para análise da sujeira, foi utilizado um dos arrays da planta, com 16 módulos e potência de $4,08 \mathrm{kWp}$. Antes do início dos testes, houve a limpeza de 8 dos módulos, enquanto os outros foram deixados sujos. Para análise, foram utilizadas a eletricidade gerada e imagens térmicas dos módulos. Comparando a geração dos módulos nos seis dias do experimento, é visto que os módulos limpos geraram $26,6 \mathrm{kWp}$ a mais do que os sujos. Além disso, em termos de temperatura na superfície dos módulos, a imagem térmica indica um aumento na temperatura de cerca de $10^{\circ} \mathrm{C}$ no módulo sujo. A Figura 10 mostra as características para os testes desenvolvidos com os módulos.

Figura 10 - Características para os testes desenvolvidos com os módulos FV limpos e sujos.

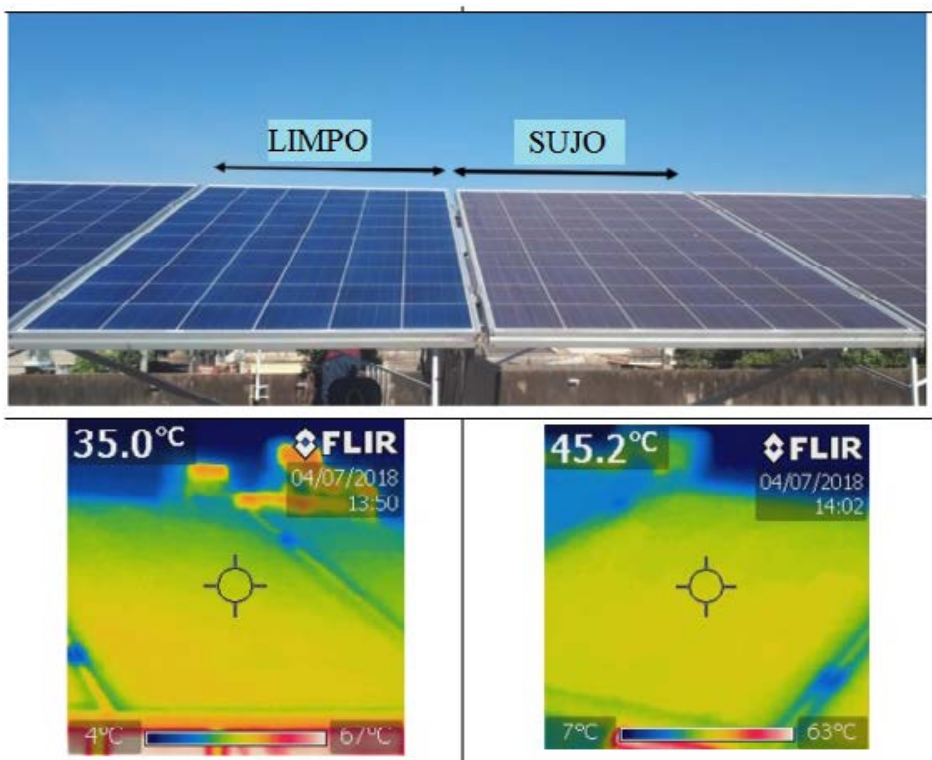

Fonte: Silva et al., 2019. 


\section{Estudos Internacionais}

Saidan et al. (2016) investigam e calculam, sob condições de tempestades de areia, o efeito da poeira no desempenho de módulos FV instalados no Laboratório de Física Solar do Centro de Pesquisa de Energia Solar em Bagdá, Iraque. Para isso, três módulos FV idênticos, do tipo m-Si de 26,7 Wp, cada, foram alocados na laje do prédio durante 30 dias. As medições foram feitas de formas diferentes para cada módulo, sendo diariamente para o primeiro módulo, semanalmente para o segundo e mensalmente para o último. Durante o experimento, cinco tempestades de areia ocorreram, e por isso o tamanho das partículas nos módulos variaram entre 1,1-1,2 mm, devido às tempestades, e 0,4-0,5 mm, durantes os dias normais. Avaliando as curvas I-V, nota-se uma elevada redução na eficiência, com uma considerada redução na corrente, sendo um decréscimo da corrente de $6 \%$ para a exposição do módulo de 1 dia e até $16,5 \%$ durante um mês de operação contínua. A Figura 11 apresenta curvas I-V sob diferentes períodos de acúmulo de sujeira.

Figura 11 - Variação da curva I-V com acúmulo de sujeira durante uma dia, uma semana, e um mês, respectivamente.

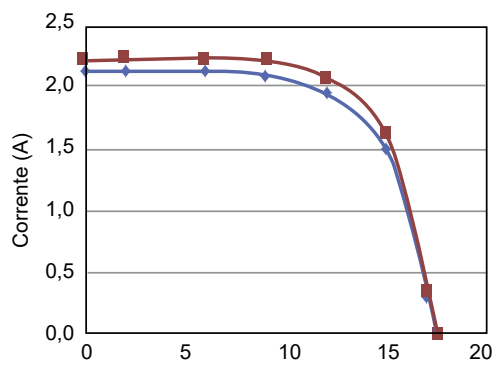

Fonte: Saidan et al., 2016.
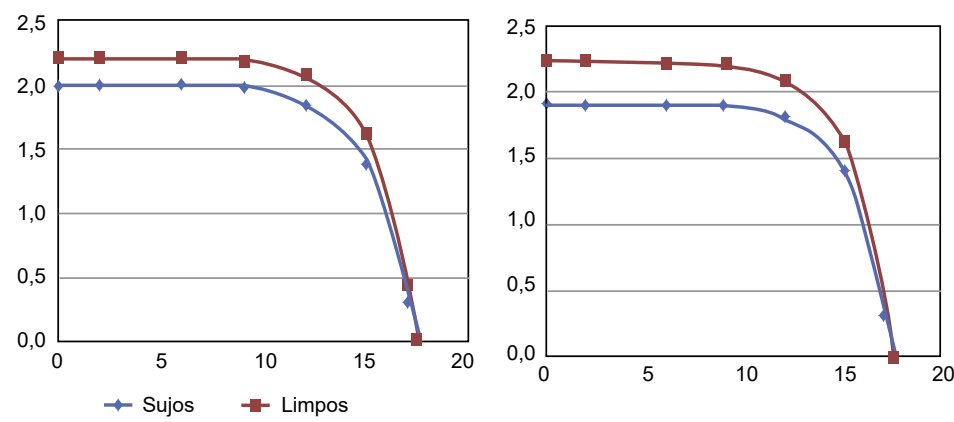

Chaichan, Mohammed e Kazem (2016) determinam a influência da poluição do ar em 3 módulos de 110 Wp cada, alocados no telhado da Universidade de Tecnologia de Bagdá, Iraque, próxima a uma rodovia de alta densidade de tráfego. Durante o experimento, um módulo foi limpo somente por chuva e vento, o outro por álcool a cada sete dias e o terceiro foi deixado para acumular sujeira. Os resultados indicam que a tensão de circuito aberto e a corrente de curto-circuito do módulo sujo degradou-se muito em comparação com o módulo limpo a cada sete dias, acarretando em uma perda de eficiência de $63,7 \%$. Analisando o módulo naturalmente limpo, seu desempenho melhorou depois de uma chuva, tendo uma perda de eficiência de $32,98 \%$ quando comparado com o módulo limpo. As inspeções de poluentes coletados mostram altas taxas de partículas de hidrocarbonetos, resultantes dos escapamentos dos carros.

Paudyal e Shakya (2016) investigam a sujidade em módulos posicionados no Instituto de Engenharia da Universidade de Tribhuvan, Lalitpur, Nepal, durante 150 dias. Foram utilizados dois módulos FV p-Si de $40 \mathrm{Wp}$ cada, sendo um módulo limpo diariamente, enquanto o outro não. Como resultado, os módulos produziram a mesma quantidade de eletricidade inicialmente, porém, à medida que os dias passaram, é observada uma considerável diferença da potência de saída entre o módulo limpo e empoeirado. Desse modo, houve um forte aumento na redução da eficiência durante o período do experimento sem chuva, cerca de $29,76 \%$, com exceção de uma leve melhora devido às gotas de orvalho. Além disso, a densidade do depósito de poeira no módulo FV representou uma variação entre $0,1047 \mathrm{~g} / \mathrm{m}^{2}$ e $9,6711 \mathrm{~g} / \mathrm{m}^{2}$.

Guan et al. (2017) realizam um experimento em um parque FV de seis fileiras de 9 móduloscada, com potência instalada de 13,2 kWp, em Xi'an, China, para investigação do efeito da deposição da sujeira na temperatura, transmitância e na potência de saída de módulos FV, na condição de com e sem carga. Sendo a metodologia utilizada diferente para cada uma das condições dos módulos, têm-se que para a condição sem carga, houve a deposição natural de sujeira por 17 dias e dois módulos de fileiras diferentes foram selecionados para limpeza e comparação. Já para a condição com carga, a superfície dos módulos de três 
fileiras foi artificialmente coberta com diferentes densidades de sujeiras. Os resultados mostram que em todas as condições a deposição de sujeira resultou em uma temperatura mais baixa e numa menor potência de saída e transmitância, e com o aumento dessa deposição, a temperatura, a potência e a transmitância do módulo diminuíam.

Menoufi et al. (2017) apresentam um estudo em módulos posicionados no telhado do Laboratório de Energias Renováveis da Faculdade de Pós-Graduação em Ciências Avançadas da Universidade Beni-Suef, em Beni-Suef, Egito. No experimento, dois módulos FV p-Si de $10 \mathrm{Wp}$ cada, foram expostos ao ambiente externo por três meses. Os módulos FV foram colocados em um ângulo de inclinação de $0^{\circ}$, sendo um limpo diariamente e o outro deixado para acumulação contínua de poeira. A densidade de sujeira encontrada no módulo foi de aproximadamente $0,2545 \mathrm{~g} / \mathrm{cm}^{2}$, com o tamanho da partícula variando entre 3,5 a $30 \mu \mathrm{m}$. Avaliando a curva I-V dos módulos, foi verificada a redução média da tensão em $39 \%$, da corrente em $45 \%$ e da potência de saída em $65 \%$ no módulo sujo. A Figura 12 mostra o estado dos módulos no fim do experimento.

Figura 12 - Módulos FV empoeirado (à esquerda) e limpo (à direita) usados no experimento.

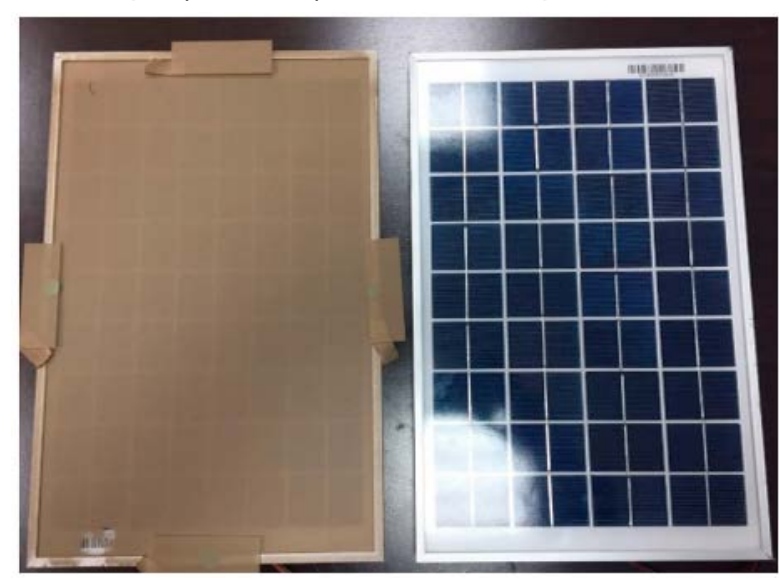

Fonte: Menoufi et al., 2017.

Conceição et al. (2018) avaliam o impacto do transporte de poeira do Saara em dois locais da zona rural de Portugal, em Évora e Alter do Chão. Para isso foram instalados vidros de alta transmitância em cada local e a sujeira encontrada, logo após os eventos de transporte de sujeira do Saara para Portugal, foi analisada. Os resultados mostram que em fevereiro de 2017 foi quando mais acumulou sujeira nos vidros e em Alter do Chão a sujeira se apresenta de forma aglomerada, sendo composta, principalmente, por alumínio, silício e oxigênio, característicos em áreas desérticas, e a acumulação de massa encontrada foi de $402 \mathrm{mg} / \mathrm{m}^{2}$. Já em Évora, as partículas de sujeira se apresentam espalhadas, os principais componentes encontrados foram silício e cálcio, da areia do deserto e do mineral calcita, e a acumulação de massa encontrada foi de $1067 \mathrm{mg} /$ $\mathrm{m}^{2}$. Analisando o impacto nos módulos, a maior queda da potência de saída e da corrente de curto circuito foi em Évora, 8\% e 3\%, respectivamente.

Jaszczur et al. (2018) investigam os efeitos da deposição de poeira e do aumento de temperatura devido à sujeira em módulos FV em Cracóvia, Polônia. A perda de eficiência foi realizada em dias ensolarados e nublados, a partir de 2 módulos p-Si de $260 \mathrm{Wp}$, sendo um limpo diariamente. Para o dia ensolarado, houve deposição de sujeira por 4 dias, enquanto que, para o dia nublado, foi por 3 dias. Considerando a temperatura do módulo, a perda de eficiência total, relacionada à deposição de poeira e à diferença de temperatura de operação, varia entre $32 \%$ e $37 \%$. Excluindo os efeitos da poeira e temperatura, a perda de eficiência é menor e varia entre 13,37 e 14,14\%. A Figura 13 apresenta a vista frontal dos módulos limpos e a vista traseira com o arranjo de termopares. 
Figura 13 - Vista frontal dos módulos FV com amostra de poeira coletada (a) e vista traseira com arranjo de termopares (b).

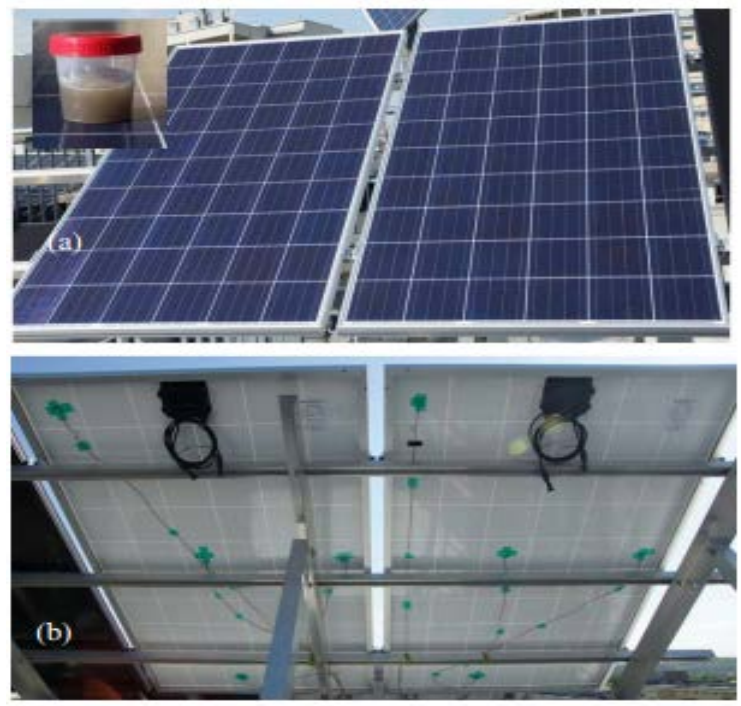

Fonte: Jaszczur et al., 2018.

Gholami et al. (2018) realizam um experimento em uma planta FV da Universidade Shahid Beheshti, em Teerã, Irã, que contém 57 módulos do tipo m-Si, divididos em 3 fileiras, e uma potência instalada de 14,5 kWp. No fim de cada semana de estudo, os autores medem a densidade média da superfície do pó nos módulos e observam que, após 70 dias sem chover, embora o nível de poeira na superfície dos módulos tenha aumentado, a taxa de deposição não foi constante, tendo a deposição de poeira ocorrido de forma mais rápida nas primeiras semanas do experimento. A densidade da superfície do pó acumulada varia de 0 $\mathrm{g} / \mathrm{m}^{2}$ a $6,0986 \mathrm{~g} / \mathrm{m}^{2}$, resultando em uma redução na potência de saída de $21,47 \%$. Também é mostrado o efeito do acúmulo da poeira sobre a corrente de curto circuito, que diminui significativamente à medida que a densidade da superfície do pó aumenta, e sobre a tensão de circuito aberto, que também diminui, mas não tem efeito perceptível.

Styszko et al. (2018) estudam o processo natural de acumulação de poeira em módulos FV em Cracóvia, Polônia, analisando a deposição de partículas dependente do tempo e sua correlação com a poluição do ar. Foram utilizados 9 módulos p-Si de $260 \mathrm{Wp}$ e a coleta da poeira foi feita em dias diferentes, variando de 1 dia a 1 semana, para cada um dos módulos. A coleta de partículas suspensas totais (TSP - total suspended particles) e de PM (particulate matter) 10, tipo de partículas inaláveis, de diâmetro inferior a $10 \mu \mathrm{m}$, também foram feitas. Os resultados mostram que a concentração de TSP variou entre 12,5 e 60,05 $\mu \mathrm{g} / \mathrm{m}^{3}$, enquanto a concentração de PM10 variou de 14 a $47 \mu \mathrm{g} / \mathrm{m}^{3}$. Já as densidades diárias de deposição de partículas variou de 7,5 a $42,1 \mathrm{mg} / \mathrm{m} 2$ e as semanais de 25,8 a $277,0 \mathrm{mg} / \mathrm{m} 2$. A taxa de acumulação de poeira atingiu cerca de $40 \mathrm{mg} / \mathrm{m}^{2} /$ dia no período sem precipitação e foi pelo menos duas vezes superior aos fluxos calculados com base nas concentrações de PM10 e TSP.

You et al. (2018) propõem um modelo de previsão de sujidade para comparar a perda de eficiência em módulos FV nas condições climáticas de sete cidades ao redor do mundo: Taichung, Tóquio, Hami, Malibu, Sanlucarla Mayor, Doha e Walkaway. As seguintes considerações foram feitas: variação temporal de um ano para todas as cidades, exceto para Doha, que foram 140 dias; três cenários de ângulo de inclinação: o ideal para cada cidade, $-10^{\circ}$ e $+10^{\circ}$; usina FV de $1 \mathrm{MW}$; intervalo de limpeza variado, com resolução mínima de 1 dia para Doha e 7 dias para as outras cidades; diâmetro médio de $20 \mu \mathrm{m}$ por volume para o tamanho de sujeira; entre outras. Nos resultados, é verificado que a eficiência reduziu na seguinte ordem crescente: Tóquio/ Walkaway, Taichung, Sanlucarla Mayor, Malibu, Hami e Doha, em que a variação do ângulo de inclinação pouco afeta esse resultado. Já o intervalo ideal de limpeza previsto varia entre 23 e 70 dias e entre 17 e 49 
dias para os métodos manual e auxiliado por máquina, respectivamente, sendo o tempo menor para Doha e o maior para Malibu, nos dois casos.

Hammoud et al. (2019) analisam os benefícios de limpezas periódicas em uma planta FV de 307,52 kWp, composta de 992 módulos m-Si, em Zahrani, Líbano. A limpeza foi realizada a cada 14 dias, começando em 15/06/2018 e terminando em 21/09/2018, por meio de um dispositivo robótico projetado. A metodologia empregada foi comparar a produção de eletricidade diária gerada durante o período de teste, em 2018, com a coletada durante o mesmo período sem limpeza, em 2017. Com a limpeza, é registrado um aumento de geração de 32,27\% durante o período de teste. A visão aérea da planta FV analisada é apresentada na Fig.14.

Figura 14 - Visão aérea da planta FV em Zahrani, Líbano.

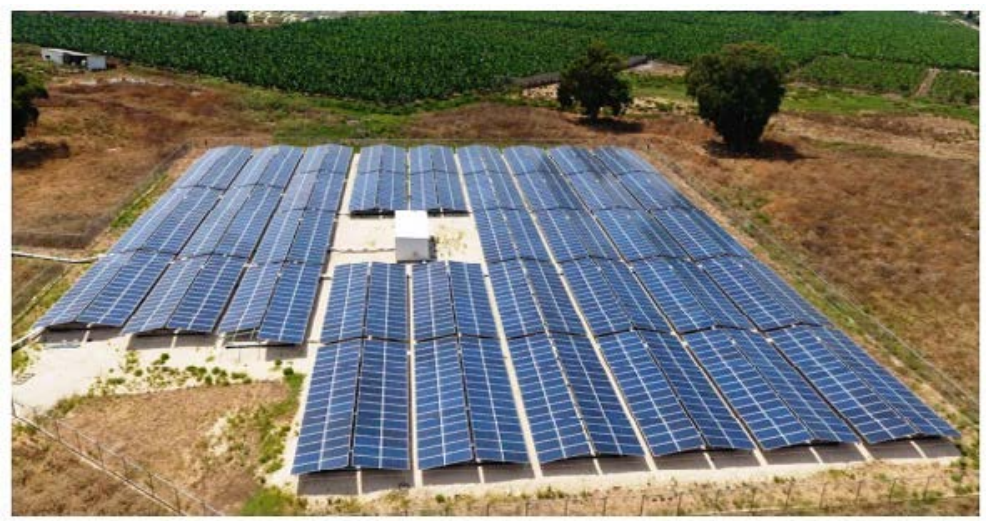

Fonte: Hammoud et al., 2019.

Jha; Tripathy (2019) estudam o impacto da sujeira, do vento e das estações do ano em uma planta FV em Kharagpur, Índia. A planta é composta por 8 módulos p-Si e possui uma potência instalada de $2 \mathrm{kWp}$. O procedimento experimental foi conduzido durante dois meses, um no verão e outro no inverno, com os módulos limpos e sujos. Desse modo, a redução na eficiência dos módulos devido à deposição de sujeira foi $51 \%$ maior no verão do que no inverno. Para comprovar que o aumento da velocidade do vento acarreta em um aumento na deposição de poeira na superfície dos módulos FV no verão, os mesmos foram expostos à uma condição de vento criFada por ventiladores de altas velocidades. Assim, a eficiência do módulo limpo no dia ventoso e ensolarado foi reduzida em aproximadamente 15\%, enquanto que, para o módulo empoeirado, a redução foi de $19,5 \%$.

Mostefaoui et al. (2019) investigam os efeitos negativos do acúmulo de poeira causado por tempestades de areia no desempenho de módulos FV em Adrar, Argélia. O experimento é dividido em duas partes. $\mathrm{Na}$ primeira, para medir a densidade de deposição de sujeira na superfície dos módulos FV, 4 módulos m-Si de $100 \mathrm{Wp}$ foram utilizados, em que a cada 2 meses houve a coleta da sujeira de um deles. A densidade de sujeira aumenta de $1,2 \mathrm{~g} / \mathrm{m}^{2}$, nos dois primeiros meses para $4,85 \mathrm{~g} / \mathrm{m}^{2}$, no final dos seis meses. Já na segunda parte, a medição dos parâmetros elétricos de 3 módulos m-Si de $100 \mathrm{Wp}$ foi realizada no final dos 6 meses, antes e depois da limpeza. Os resultados mostram que a diferença entre a potência, a corrente de curto circuito e a eficiência dos módulos, limpos e sujos, varia entre $31 \%$ e $29 \%$, $26 \%$ e $24 \%$, e $32 \%$ e $29 \%$, respectivamente.

Zitouni et al. (2019) avaliam o desempenho de um planta FV de 16,5 kWp, em Ben Guerir, Marrocos, durante dois períodos, seco e chuvoso. A planta é composta por três fileiras de 23 módulos, cada, e somente duas das fileiras foram utilizadas no experimento, uma foi limpa duas vezes na semana e a outra foi deixada suja durante todo o estudo. A análise do desempenho foi realizada por meio da diferença entre a eletricidade produzida dos módulos limpos e sujos e por meio da relação de sujidade. No período seco, a diferença da eletricidade produzida atingiu um valor máximo de $16 \%$ e no período chuvoso, um máximo de $2 \%$. Já a relação de sujidade, que varia de forma regressiva a partir de 1 (estado limpo), no período seco, atingiu, em média, $0,32 \% /$ dia e, no período chuvoso, atingiu uma média de $0,02 \% / d i a$. A composição química da sujeira 
foi analisada e os principais elementos encontrados foram silício, cálcio e oxigênio. Na Figura 15 é mostrada a coleta da sujeira dos módulos.

Figura 15 - Coleta da sujeira dos módulos.

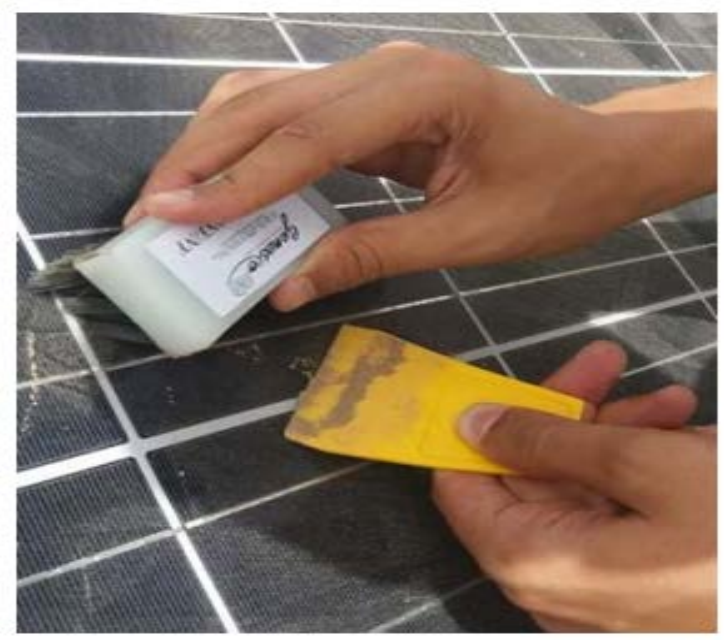

Fonte: Zitouni et al., 2019.

\section{Análise geral dos trabalhos mencionados}

Dos 23 trabalhos considerados no presente artigo, 9 brasileiros e 14 internacionais, a maioria utilizou a metodologia de comparar a geração de eletricidade entre módulos limpos e sujos. Dos experimentos brasileiros, 6 foram realizados em Minas Gerais, estado que possui a maior potência instalada FV do país (ANEEL, 2019). Na região Nordeste, região com os mais altos índices de irradiação do Brasil, apenas 1 trabalho foi realizado sobre o assunto. Dos internacionais, 10 são de locais próximos a áreas desertas.

Para mitigação da sujeira por meio da limpeza manual, apenas 2 artigos relatam o tempo ideal para limpeza. You et al. (2018) propõem intervalos que variam entre 23 e 70 dias, dependendo do local de instalação da planta FV. Júnior, Cruz e Amaral (2018) sugerem intervalos não menores do que 15 dias.

Os elementos químicos encontrados mais recorrentes na sujeira foram silício e cálcio, enquanto o tamanho das partículas variaram entre $2 \mu \mathrm{m}$ e $1,1 \mathrm{~mm}$. Na Figura 16 é mostrada a porcentagem dos trabalhos que analisaram a composição química e o tamanho das partículas e a porcentagem dos trabalhos que utilizaram a forma natural ou artificial para deposição da sujeira.

Figura 16 - Porcentagem dos artigos que analisam a composição química (a) o tamanho das partículas (b) e a forma de deposição da sujeira (c).
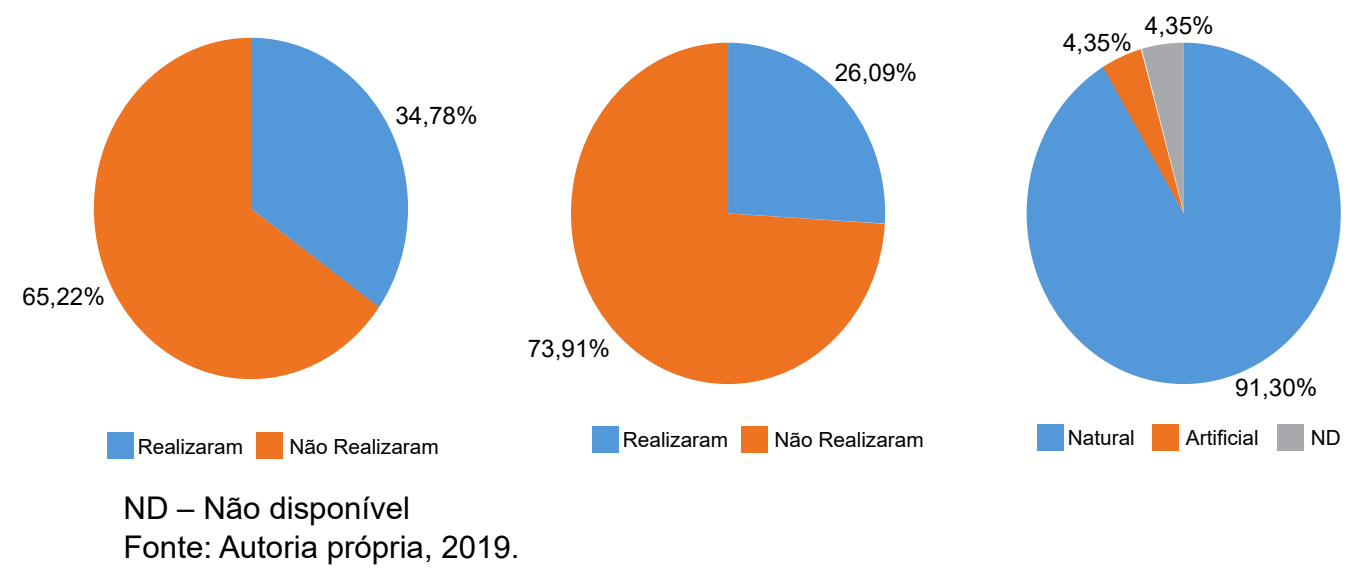


\section{Avaliação do impacto da sujidade em módulos FV instalados no LEA-UFC}

Visando a avaliação do impacto da sujidade nos módulos FV localizados no LEA-UFC, inicialmente, é realizada uma comparação entre dados diários de irradiação no plano horizontal e de precipitação com o objetivo de identificar os dias com alta irradiação antes e depois de um período com chuva. A partir disso, os gráficos de irradiância dos dias identificados no passo anterior são comparados a fim de se obter gráficos que correspondam a dias com o mínimo de nuvens possível.

A partir da potência máxima atingida no dia pelos módulos FV, assim como da eletricidade gerada, da área efetiva dos módulos e da irradiação, os parâmetros que avaliam o desempenho de uma planta FV são calculados: eficiência, YIELD, PR e SR. Importante citar que a planta FV em estudo foi instalada no dia 28/09/2018 e os dados passaram a ser coletados a partir do dia 29/09/2018.

Comparando os dados de irradiação no plano horizontal e a precipitação ao longo do período do dia 29/09/2018 até o dia 12/12/2018, é possível concluir que praticamente não choveu em outubro e novembro. Em dezembro, até o dia analisado, houve 6 dias com chuva (Fig. 17). No presente trabalho, só são consideradas precipitações diárias maiores do que $0,3 \mathrm{~mm}$, pois precipitações menores do que esse valor não possuem efeito de limpeza sobre os módulos (MICHELI; MULLER, 2017).

Figura 17 - Gráfico da irradiação diária e precipitação entre 29/09/2018 e 29/12/2018.

\section{Título do Gráfico}

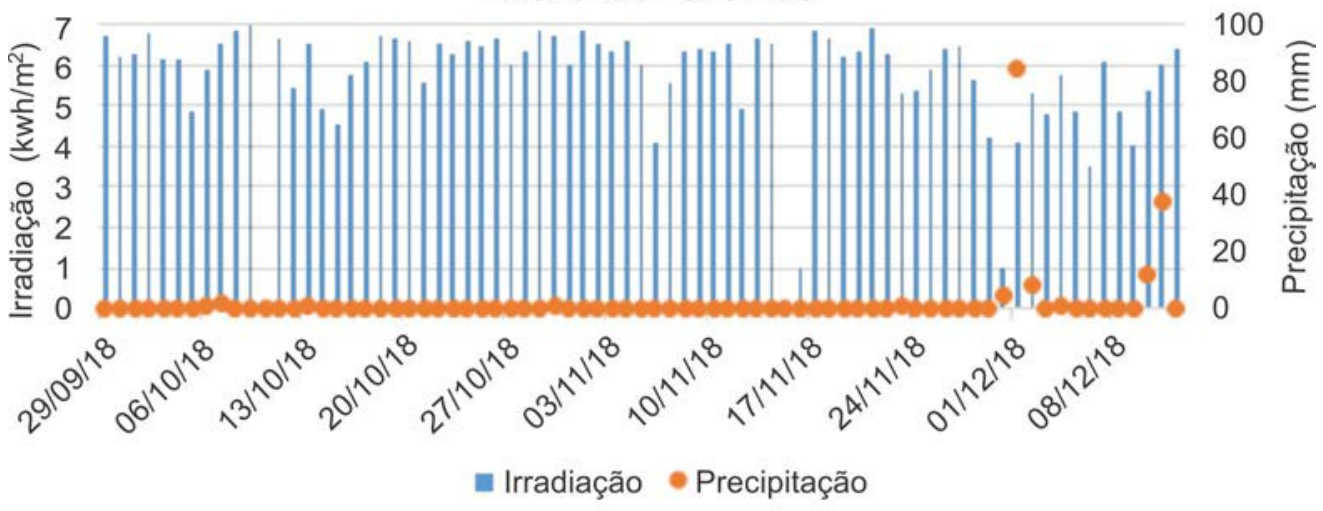

Fonte: Autoria própria, 2019.

Os dias de céu claro selecionados são:

-30/09: módulos instalados em 28/09 e chuva em 29/09;

- 02/10: dia de céu claro depois da chuva em 01/10 e mais próximo antes da chuva em 07/10;

- 08/10: dia seguinte ao dia de chuva em 07/10;

-24/10: 17 dias depois da chuva em 07/10;

-22/11: 23 dias depois da chuva em 30/10;

-27/11: dia de céu claro mais próximo ao dia da chuva em 23/11;

-12/12: dia de céu claro depois das chuvas nos dias 01, 02, 10 e 11/12;

Na Figura 18 são apresentadas a irradiância no plano horizontal e a potência FV de cada dia selecionado. Os valores oscilam bastante no período da manhã, o que pode ser explicado pela presença de nuvens. Segundo Teixeira (2008), o fenômeno frente de brisa em Fortaleza forma nuvens na madrugada e início da manhã, mas durante a tarde a presença de nuvens é menor, por essa frente avançar na direção sul do estado. Além disso, a partir dessa figura vê-se que há uma sobreposição entre as curvas de irradiância e potência, que é coerente pois a potência FV gerada pelos módulos FV depende diretamente da irradiação que incide sobre a superfície dos mesmos. 
Figura 18 - Gráficos da irradiância no plano horizontal e da potência FV dos dias selecionados.

$30 / 09 / 2018$

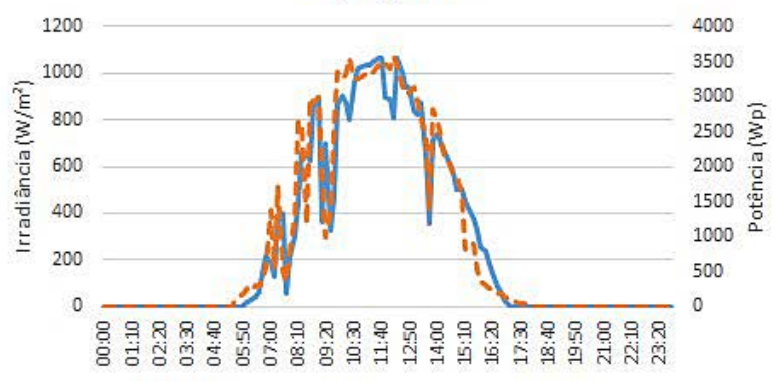

—Irradiância _- - Potência

$08 / 10 / 2018$

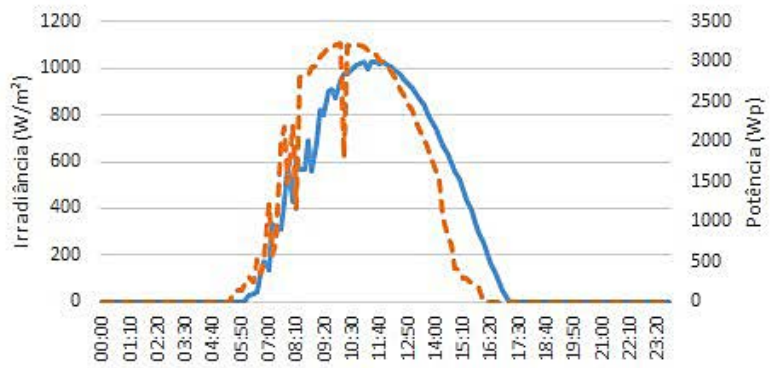

Irradiância - - Potência

$22 / 11 / 2018$

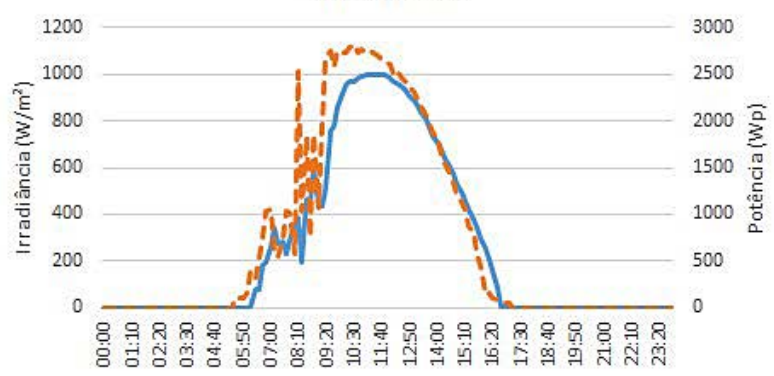

$02 / 10 / 2018$

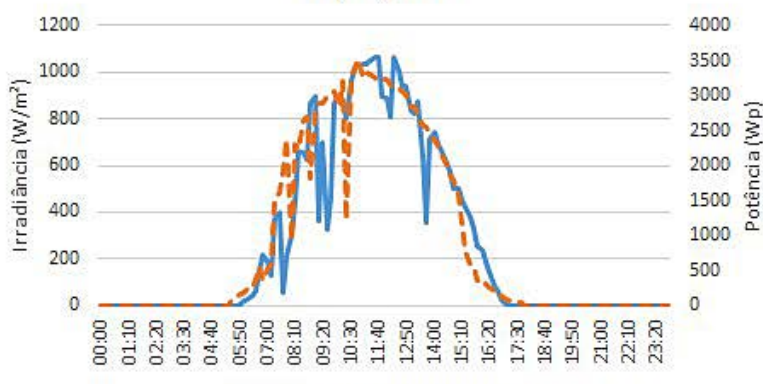

—Irradiância - - - Potência

$24 / 10 / 2018$

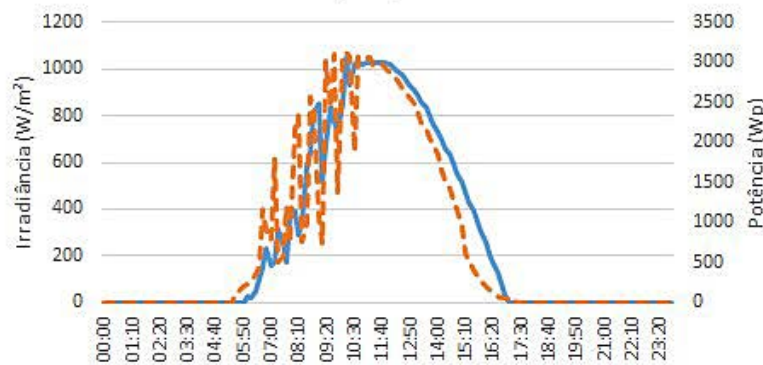

—Irradiância - - - Potência

$27 / 11 / 2018$

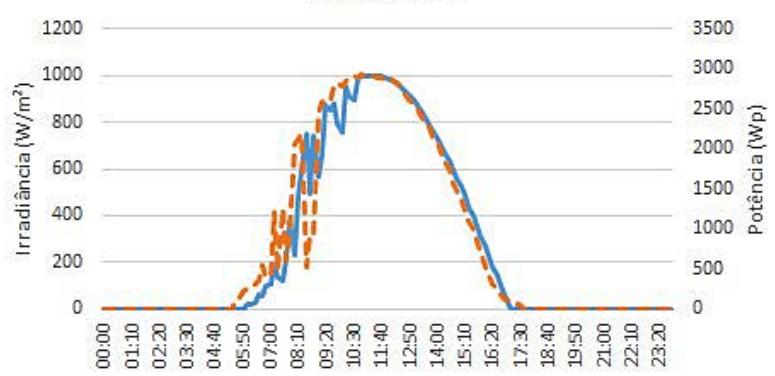

Irradiância - - - Potência

$12 / 12 / 2018$

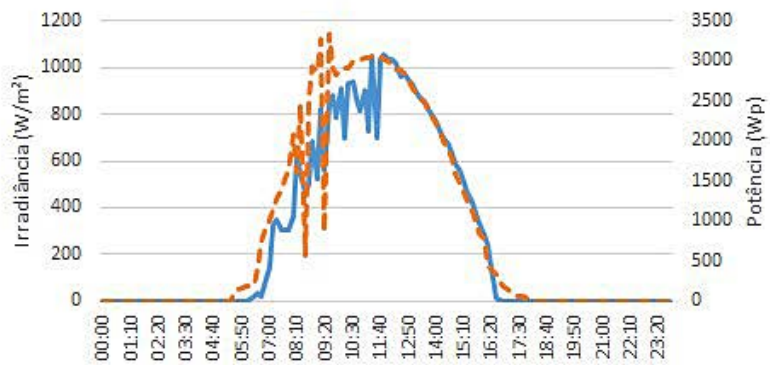

- Irradiância - - Potência

Fonte: Autoria própria, 2019.

Na Tabela (3) são mostrados os parâmetros dos dias selecionados utilizados para os cálculos de desempenho da planta FV, em que a área efetiva dos módulos é de $21,03 \mathrm{~m}^{2}$ e a potência FV instalada é de $3,90 \mathrm{kWp}$ 
Tabela 3: Parâmetros dos dias selecionados.

\begin{tabular}{l|c|c|c|c|c|c|c}
\hline Dia & $30 / 09$ & $02 / 10$ & $08 / 10$ & $24 / 10$ & $22 / 11$ & $27 / 11$ & $12 / 12$ \\
\hline Irradiação diária $\left(\mathrm{kWh} / \mathrm{m}^{2}\right)$ & 6,25 & 6,79 & 6,87 & 6,61 & 6,28 & 6,48 & 6,45 \\
\hline Eletricidade Gerada diária $(\mathrm{kWh})$ & 20,5 & 22 & 22 & 18,1 & 18 & 19,8 & 21,1 \\
\hline Pmax diária $(\mathrm{kWp})$ & 3,57 & 3,52 & 3,22 & 3,13 & 2,81 & 2,93 & 3,32 \\
\hline
\end{tabular}

A partir desses dados e das métricas de desempenho apresentadas na seção 2, os cálculos para analisar o desempenho da planta FV do LEA-UFC são realizados e os resultados são mostrados na Tab. (4).

Tabela 4: Resultados das métricas de desempenho.

\begin{tabular}{l|c|c|c|c|c|c|c}
\hline Dia & $30 / 09$ & $02 / 10$ & $08 / 10$ & $24 / 10$ & $22 / 11$ & $27 / 11$ & $12 / 12$ \\
\hline YIELD (kWh/kWp) & 5,25 & 5,64 & 5,64 & 4,64 & 4,61 & 5,07 & 5,41 \\
\hline PR (\%) & 84,10 & 83,08 & 82,11 & 70,21 & 73,49 & 78,35 & 83,88 \\
\hline Eficiência (\%) & 15,60 & 15,41 & 15,23 & 13,02 & 13,63 & 14,53 & 15,56 \\
\hline SR & 1,00 & 0,98 & 0,90 & 0,88 & 0,79 & 0,82 & 0,93 \\
\hline
\end{tabular}

Pode-se concluir que os melhores YIELD são de 5,64 kWh/kWp, dos dias 02/10 e 08/10, e o pior foi no dia 22/11, de 4,61 kWh/kWp, após 23 dias sem chuva. O melhor PR foi de $84,10 \%$, do dia 30/09, e o pior foi de $70,21 \%$, no dia $24 / 10$, após 17 dias sem chuva. O dia com maior eficiência foi no dia $30 / 09$, de $15,60 \%$, e o pior foi no dia 24/10, de 13,02\%. Por último, o maior valor de SR foi 1,00, no dia 30/09, e o menor foi de 0,79 , em 22/11. Em geral, o dia em que a planta teve seu melhor desempenho foi em 30/09, início do estudo, e os dias com piores desempenhos foram em 24/10 e 22/11, depois de 17 e 23 dias sem chuva, respectivamente.

Comparando a eletricidade gerada, a irradiação e as métricas de desempenho do dia de melhor desempenho (30/09) com os dias de piores (24/10 e 22/11):

- Comparação entre 30/09 e 24/10: aumento de 5,45\% da irradiação, porém redução de $11,71 \%$ da eletricidade gerada e do YIELD, de $16,52 \%$ do PR e da eficiência, e 12,36\% do SR;

- Comparação entre 30/09 e 22/11: aumento de 0,48\% da irradiação e redução de $12,20 \%$ da eletricidade gerada e do YIELD, de $6,84 \%$ do PR e da eficiência, e de $21,22 \%$ do SR.

$\mathrm{Na}$ Tabela (4) a partir do dia 22/11 o desempenho da planta FV melhora devido às chuvas ocorridas no dia 23/11 e nos primeiros dias de dezembro. Comparando a eletricidade gerada, a irradiação e as métricas de desempenho dos dias 22/11 e 27/11 e dos dias 27/11 e 12/12, têm-se:

- Comparação entre 22/11 e 27/11: aumento de 1,70\% da irradiação, de 9,09\% da eletricidade gerada e do YIELD, 6,20\% do PR e da eficiência, e 4,12\% do SR.

- Comparação entre 27/11 e 12/12: redução de 0,46\% da irradiação, aumento de 6,16\% da eletricidade gerada e do YIELD, de 6,60 do PR e da eficiência, e de $11,72 \%$ do SR.

\section{Conclusão}

A sujeira, depois da irradiação e da temperatura ambiente, é o fator que mais impacta o desempenho dos módulos FV. A partir dos artigos analisados no Estado da Arte do presente artigo, pode-se concluir que as condições ambientais do local em que está instalada a planta FV, assim como as variações sazonais, impactam diretamente a quantidade, o tipo e o tamanho das partículas de sujeira que são encontradas sobre os módulos FV. Além disso, a deposição de sujeira na superfície dos módulos está fortemente atrelada à poluição do ar.

Desse modo, sabendo a importância do impacto da sujidade no desempenho de módulos FV, uma análise foi realizada para quantificar as perdas devido à sujeira sobre a superfície dos módulos de uma planta 
FV instalada no Laboratório de Energias Alternativas da Universidade Federal do Ceará (LEA-UFC), campus do Pici da UFC, em Fortaleza, próxima a uma avenida de grande movimento e com vegetação arredores.

A partir dos resultados obtidos, conclui-se que com o acúmulo de sujeira sobre os módulos, mesmo quando a irradiação aumenta, há diminuição das métricas de desempenho, podendo diminuir em até $11,71 \%$ (20,5 kWh em 30/09 e 18,1 kWh em 24/10) a eletricidade gerada e $16,52 \%$ a eficiência da planta (15,60\% em $30 / 09$ e 13,02\% em 24,10) em 17 dias sem chuvas. Quando os módulos estão limpos, após ocorrência de chuva de $0,6 \mathrm{~mm}$ no dia 23/11, mesmo com uma diminuição não significativa da irradiação, é registrado um aumento significativo das métricas de desempenho, em que um aumento de apenas $1,70 \%$ de irradiação gera um aumento de $9,09 \%$ da eletricidade gerada e de $6,20 \%$ da eficiência da planta.

\section{Agradecimentos}

Danielly Norberto Araújo e Ivonne M. Dupont agradecem à CAPES pelas bolsas de mestrado e doutorado, respectivamente; Paulo C. M. Carvalho agradece ao CNPq pela bolsa de pesquisador concedida e pelo suporte financeiro ao projeto (420133/2016-0 Universal 01/2016). Os autores agradecem à Estação Agroclimatológica do Centro de Ciências Agrárias da UFC pela disponibilidade dos dados de precipitação e à UFC pela disponibilidade de laboratórios e equipamentos.

\section{Referências}

AFONSO, M. M. D. Estudo da degradação e desempenho de módulos fotovoltaicos. 2015. Dissertação (Mestrado em Engenharia Elétrica) - Universidade Federal do Ceará, Fortaleza, 2015.

ARAÚJO, A. J. N.; RANKA, N. I.; BUENO, T. B. A. Análise dos fatores de perdas nos sistemas fotovoltaicos conectados à Rede Elétrica em Curitiba (Trabalho de Conclusão de Curso) - , Universidade Tecnológica Federal do Paraná, Curitiba, 2016.

BARBOSA, E. R.; FARIA, M. dos S. F. de; GONTIJO, F. de B. Influência da sujeira na geração fotovoltaica. In: CONGRESSO BRASILEIRO DE ENERGIA SOLAR, 7. 2018, Gramado. Anais [...]. Disponível em: https://anaiscbens.emnuvens.com.br/cbens/article/view/655. Acesso em 15 abr. 2019.

BRAGA, D. S. et al. Relação entre distribuições não uniformes de sujidade e tecnologias silício cristalino e telureto de cádmio. In: CONGRESSO BRASILEIRO DE ENERGIA SOLAR, 7. 2018, Gramado. Anais [...]. Disponível em: https://anaiscbens.emnuvens.com.br/cbens/article/view/223. Acesso em 15 abr. 2019.

CHAICHAN, M. T.; MOHAMMED, B. A.; KAZEM, H. A. Effect of pollution and cleaning on photovoltaic performance based on experimental study. International Journal of Scientific and Engineering Research, [s. I.], v. 6, p. 594-601, 2015.

CONCEIÇÃO, R. et al. Saharan dust transport to Europe and its impact on photovoltaic performance: a case study of soiling in Portugal. Solar Energy, [s. I.], v. 160, p. 94-102, nov. 2018.

COSTA, S. C. S.; DINIZ, A. S. A. C.; KAZMERSKI, L. L. Dust and soiling issues and impacts relating to solar energy systems: literature review update for 2012-2015. Renewable and Sustainable Energy Reviews, [s. I.], v. 63, p. 33-61, 2016.

COSTA, S. C. S.; DINIZ, A. S. A. C.; KAZMERSKI, L. L. Solar energy dust and soiling R\&D progress: Literature review update for 2016. Renewable and Sustainable Energy Reviews, [s. I.], v. 82, n. april, p. 2504-2536, 2018.

COSTA, S. C. S. et al. Avaliação da sujidade em módulos fotovoltaicos em Minas Gerais. In: CONGRESSO BRASILEIRO DE ENERGIA SOLAR, 7., 2018, Gramado. Anais [...]. Disponível em: https://anaiscbens. emnuvens.com.br/cbens/article/view/191. Acesso em 15 abr. 2019. 
DARWISH, Z. A. et al. Effect of dust pollutant type on photovoltaic performance. Renewable and Sustainable Energy Reviews, [s. I.], v. 41, p. 735-744, 2015.

FRAGA, M. M. et al. Analysis of the soiling effect on the performance of photovoltaic modules on a soccer stadium in Minas Gerais, Brazil. Solar Energy, [s. I.], v. 163, n. October 2017, p. 387-397, 2018.

GHAZI, S.; SAYIGH, A.; IP, K. Dust effect on flat surfaces - a review paper. Renewable and Sustainable Energy Reviews, [s. I.], v. 33, p. 742-751, 2014.

GHOLAMI, A. et al. Experimental investigation of dust deposition effects on photo-voltaic output performance. Solar Energy, [s. I.], v. 159, n. november 2017, p. 346-352, 2018.

GOOGLE. Google Earth software. Disponível em: http://earth.google.com/. Acesso em: abr. 2019.

GUAN, Y. et al. In-situ investigation of the effect of dust deposition on the performance of polycrystalline silicon photovoltaic modules. Renewable Energy, [s. I.], v. 101, p. 1273-1284, 2017.

HAMMOUD, M. et al. Effect of dust cleaning on the enhancement of the power generation of a coastal PVpower plant at Zahrani Lebanon. Solar Energy, [s. I.], v. 184, n. april, p. 195-201, 2019.

HICKEL, B. M. et al. Análise da influência do acúmulo de sujeira sobre diferentes tecnologias de módulos FV: revisão e medições de campo. In: CONGRESSO BRASILEIRO DE ENERGIA SOLAR, 7. 2016, Belo Horizonte. Anais [...]. Disponível em: http://www.abens.org.br/CBENS2016/anais/anais/ trabalhos/26780final.pdf. Acesso em: 15 abr. 2019.

ILSE, Klemens K. et al. Fundamentals of soiling processes on photovoltaic modules. Renewable and Sustainable Energy Reviews, [s. I.], v. 98, n. january, p. 239-254, 2018.

JAMIL, W. J. et al. Performance degradation of photovoltaic power system: Review on mitigation methods. Renewable and Sustainable Energy Reviews, [s. I.], v. 67, p. 876-891, 2017.

JASZCZUR, Marek et al. The field experiments and model of the natural dust deposition effects on photovoltaic module efficiency. Environmental Science and Pollution Research, [s. I.], v. 26, n. 9, p. $8402-$ $8417,2019$.

JASZCZUR, M. et al. Study of dust deposition and temperature impact on solar photovoltaic module. In: MATEC WEB OF CONFERENCES. EDP SCIENCES, 2018. Anais [...]. Disponível em: https://search. proquest.com/docview/2140098655?pq-origsite=gscholar. Acesso em: 15 abr. 2019.

JHA, Aprajeeta; TRIPATHY, P. P. Heat transfer modeling and performance evaluation of photovoltaic system in different seasonal and climatic conditions. Renewable Energy, [s. I.], v. 135, p. 856-865, 2019.

JINKO SOLAR. JKM330PP-72-315-330 Watt. Disponível em: http://jinkosolar.com. Acesso em: 15 abr. 2019.

JOHN, J. J. Characterization of soiling loss on photovoltaic modules, and development of a novel cleaning system. Tese (Doutorado) — Indian Institute of Technology Bombay, Mumbai, 2015.

KALDELLIS, John K.; KAPSALI, Marina; KAVADIAS, Kosmas A. Temperature and wind speed impact on the efficiency of $\mathrm{PV}$ installations. Experience obtained from outdoor measurements in Greece. Renewable Energy, v. 66, p. 612-624, 2014.

KUMAR, R.; SINHA, S. K.; PANDEY, K. Effect of temperature, irradiation, humidity and wind on ideal/ double diode PV system performance. In: INTERNATIONAL CONFERENCE ON POWER ELECTRONICS, INTELLIGENT CONTROL AND ENERGY SYSTEMS (ICPEICES), 1., Delhi, 2016. Anais [...]. Disponível em: https://ieeexplore.ieee.org/document/7853503. Acesso em: 15 abr. 2019. 
LANNOY, A.; PROCACCIA, H. Evaluation et maîtrise du vieillissement industriel. Lavoisier, 2005.

MENOUFI, Karim et al. Dust accumulation on photovoltaic panels: a case study at the East Bank of the Nile (Beni-Suef, Egypt). Energy Procedia, [s. I.], v. 128, p. 24-31, 2017.

MICHELI, L.; MULLER, M. An investigation of the key parameters for predicting PV soiling losses. Progress in photovoltaics: research and applications, [s. I.], v. 25, p. 291-307, 2017.

MOSTEFAOUI, M. et al. Effect of sand dust accumulation on photovoltaic performance in the Saharan environment: southern Algeria (Adrar). Environmental Science and Pollution Research, [s. I.], v. 26, n. 1, p. 259-268, 2019.

MUNOZ, M. A. et al. Early degradation of silicon PV modules and guaranty conditions. Solar energy, [s. I.], v. 85, n. 9 , p. 2264-2274, 2011.

MUSSARD, M.; AMARA, M. Performance of solar photovoltaic modules under arid climatic conditions: a review. Solar Energy, [s. I.], v. 174, n. August, p. 409-421, 2018.

PAUDYAL, B. R.; SHAKYA, S. R. Dust accumulation effects on efficiency of FPV modules for off grid purpose: a case study of Kathmandu. Solar Energy, [s. I.], v. 135, p. 103-110, 2016.

RAZYKOV, T. M. et al. Solar photovoltaic electricity: current status and future prospects. Solar Energy, [s. I.], v. 85, n. 8, p. 1580-1608, 2011.

ROMANHOLO, P. V. V. et al. Sujidade depositada sobre módulos fotovoltaicos instalados em goiânia: morfologia e composição química. In: Congresso Brasileiro de Energia Solar, 7. 2018, Gramado. Anais [...]. Disponível em: https://anaiscbens.emnuvens.com.br/cbens/article/view/227. Acesso em: 15 abr. 2019.

SAID, S. A. M. et al. The effect of environmental factors and dust accumulation on photovoltaic modules and dust-accumulation mitigation strategies. Renewable and Sustainable Energy Reviews, [s. I.], v. 82, n. oct. 2017, p. 743-760, 2018.

SAIDAN, M. et al. Experimental study on the effect of dust deposition on solar photovoltaic panels in desert environment. Renewable Energy, [s. I.], v. 92, p. 499-505, 2016.

SARIKH, S. et al. Fault diagnosis in a photovoltaic system through IV characteristics analysis. In: INTERNATIONAL RENEWABLE ENERGY CONGRESS, 9., 2018, Hammamet. Anais [...]. Disponível em: https://ieeexplore.ieee.org/abstract/document/8362572. Acesso em: 15 abr. 2019.

SILVA, A. M. et al. The study and application of evaluation methods for photovoltaic modules under real operational conditions, in a region of the Brazilian southeast. Renewable Energy, [s. I.], v. 138, p. 11891204, 2019.

SINHA, P. et al. Environmental variables affecting solar photovoltaic energy generation in Morocco. In: INTERNATIONAL RENEWABLE AND SUSTAINABLE ENERGY CONFERENCE. 2014, Ouarzazate. Anais [...]. Disponível em: https://ieeexplore.ieee.org/abstract/document/7059897. Acesso em: 15 abr. 2019.

SOARES JÚNIOR, J. G.; CRUZ, S. R.; AMARAL, L. S. Impacto da sujidade sobre o desempenho de sistemas fotovoltaicos. In: CONGRESSO BRASILEIRO DE ENERGIA SOLAR, 7. 2018, Gramado. Anais [...]. Disponível em: https://anaiscbens.emnuvens.com.br/cbens/article/view/123. Acesso em: 15 abr. 2019. STYSZKO, K. et al. An analysis of the dust deposition on solar photovoltaic modules. Environmental Science and Pollution Research, p. 1-9, 2018.

TEIXEIRA, R. F. B. O fenômeno da brisa e sua relação com a chuva sobre Fortaleza-CE. Revista Brasileira de Meteorologia, São José dos Campos, v. 23, n. 3, p. 282-291, 2008. 
TONOLO, É. A.; MARIANO, J. D. A. Análise do efeito do acúmulo de sujeira nos sistemas fotovoltaicos da Utfpr - Câmpus Curitiba. In: CONGRESSO BRASILEIRO DE ENERGIA SOLAR, 7., 2018, Gramado. Anais [...]. Disponível em: https://anaiscbens.emnuvens.com.br/cbens/article/view/183. Acesso em: 15 abr. 2019.

YOU, S. et al. On the temporal modelling of solar photovoltaic soiling: energy and economic impacts in seven cities. Applied Energy, [s. I.], v. 228, n. june, p. 1136-1146, 2018.

ZITOUNI, H. et al. Experimental investigation of the soiling effect on the performance of monocrystalline photovoltaic systems. Energy Procedia, [s. I.], v. 157, n. 2018, p. 1011-1021, 2019.

\section{Sobre os autores}

\section{Danielly Norberto Araujo}

Atualmente, é mestranda no Programa de Pós-Graduação em Engenharia Elétrica da Universidade Federal do Ceará (UFC), na área de sistemas elétricos de potência. Possui graduação em Engenheira Elétrica (2017), com ênfase em eletrotécnica, pela Universidade Federal de Campina Grande (UFCG). Técnica em Eletrotécnica (2012) pelo Instituto Federal do Ceará (IFCE). Seus interesses são: geração distribuída, geração solar fotovoltaica e sistemas de armazenamento de energia.

\section{Paulo Cesar Marques de Carvalho}

Doutor em Engenharia Elétrica pela Universidade de Paderborn, Alemanha (1997). Atualmente, é professor titular do Departamento de Engenharia Elétrica da Universidade Federal do Ceará. Possui graduação em Engenharia Elétrica pela Universidade Federal do Ceará (1989), mestrado em Engenharia Elétrica pela Universidade Federal da Paraíba (1992). Tem atividades de ensino, pesquisa e extensão nos temas: geração fotovoltaica, geração eólica e biodigestores. Coordena o Laboratório de Energias Alternativas da UFC. Bolsista de produtividade em pesquisa do CNPq.

\section{Ivonne Montero Dupont}

Doutoranda no Programa de Pós-Graduação em Engenharia Elétrica da Universidade Federal do Ceará, na área de sistemas Linux embarcados aplicados a energias renováveis. Possui graduação em Engenharia da Computação na Universidade Tecnológica da Habana José Antonio Echeverría (2014), Habana, Cuba. Trabalhou como Especialista em Ciência da Computação desde 2006 até 2015 na Empresa de Telecomunicaçoes de Cuba. Tem experiência na área de monitoramento e programação em várias linguagens (C, Java, PHP, Python), também na área de administração de aplicações informáticas (SAP), administração de bancos de dados (PostgreSQL, MySQL, Oracle) e redes de computadores. Tem experiência em administração de serviços em Windows e Linux.

Recebido em: 08.05.2019

Aceito em: 23.08.2019 